\title{
Flow and windage due to bolts on a rotating disc
}

Sulfickerali Noor Mohamed

s.noormohamed@surrey.ac.uk
John Chew

j.chew@surrey.ac.uk
Nick Hills

n.hills@surrey.ac.uk

Thermo-Fluid Systems UTC, Faculty of Engineering and Physical Science, University of Surrey, Guildford, Surrey, GU2 7XH, UK

\section{Abstract}

The cooling air in a rotating machine is subject to windage as it passes over the rotor surface, particularly for cases where non-axisymmetric features such as boltheads are encountered. The ability to accurately predict windage can help reduce the quantity of cooling air required, resulting in increased efficiency. Previous work has shown that steady CFD solutions can give reasonable predictions for the effects of bolts on disc moment for a rotor-stator cavity with throughflow but flow velocities and disc temperature are not well predicted. Large fluctuations in velocities have been observed experimentally in some cases. Time-dependent CFD simulations reported here bring to light the unsteady nature of the flow. Unsteady Reynolds averaged Navier-Stokes (URANS) calculations for $120^{\circ}$ and $360^{\circ}$ models of the rotor-stator cavity with 9 and 18 bolts were performed in order to better understand the flow physics. Although the rotor-stator cavity with bolts is geometrically steady in the rotating frame of reference, it was found that the bolts generate unsteadiness which creates time-dependent rotating flow features within the cavity. At low throughflow conditions, the unsteady flow significantly increases the average disc temperature.

Key Words: Windage, Rotor-stator, Disc cavity, Unsteady flow, CFD, Heat transfer, Rotating Stall. 
For submission to the Journal of Mechanical Engineering Science (Part C, Proc. IMechE)

\section{INTRODUCTION}

The cooling air in a gas turbine engine or other rotating machines will be heated by work transfer associated with drag due to viscous and pressure forces on the rotating components. Protrusions on the rotor surface, such as bolt-heads, directly increase this windage heating, and protrusions on stators can more indirectly increase rotor windage through modification of fluid velocity. For efficient use of cooling air it is desirable to minimize windage heating and accurately account for this effect in design calculations. As previous studies have indicated some differences between computational fluid dynamics (CFD) predictions of flow in rotor-stator disc cavities with measurements, the present study was undertaken to better understand this problem.

Early experimental studies on friction losses due to plane rotating discs were carried out by Daily and Nece [1] and Daily et al. [2]. Daily and Nece considered an enclosed rotating disc without throughflow, while Daily et al. considered the effect of an imposed radial outflow. For incompressible flow the problem can be characterized by a rotational Reynolds number $\operatorname{Re}_{\emptyset}\left(=\frac{\rho \omega \mathrm{b}^{2}}{\mu}\right)$, a mass flow parameter or throughflow Reynolds number $\mathrm{C}_{\mathrm{w}}\left(=\frac{\dot{\mathrm{m}}}{\mu \mathrm{b}}\right)$, and non-dimensional parameters describing the disc cavity geometry. From integral momentum methods using $1 / 7$ th power law velocity profiles, such as that derived for the free rotating disc by von Karman [3], it may be shown that the throughflow parameter $\lambda\left(=\frac{C_{w}}{\operatorname{Re}_{\varnothing}{ }^{0.8}}\right)$ is of particular importance, and Daily et al. utilized this result in correlating their experimental data. For $\lambda=0.22$ the imposed flow equals free disc entrainment given by von Karman's solution. There are several published steady, axisymmetric CFD validation studies on plane disc cavities. 
For submission to the Journal of Mechanical Engineering Science (Part C, Proc. IMechE)

For example, Chew and Vaughan [4] showed reasonable agreement with Daily and Nece's and Daily et al's disc moment and velocity measurements. Virr et al. [5] extended CFD validation to further rotating disc flows including Millward and Robinson's [6] heat transfer measurements for plane rotating disc. Virr et al, used the k- $\varepsilon$ model with two near-wall treatments. For high Reynolds numbers, conventional wall functions were found to give acceptable results. A two-layer model, using a k- $\ell$ formulation near the wall was preferred for lower Reynolds number flows.

Although steady CFD models have been shown to give reasonable results for many rotating disc flows, there is now considerable interest in unsteady flow effects. As noted, for example, by Greenspan [7] rotating flows are susceptible to wave formation and this has been apparent in recent research on rotor-stator disc cavities with rim seal ingestion. For example, Cao et al. [8] and Jakoby et al. [9] have observed large scale flow structures in disc cavities with ingestion. These rotate at a lower speed than the disc. In more fundamental research studies, Czarny et al. [10] and Craft et al. [11] have observed two and three lobed structures inside a simple rotor-stator cavity.

As will be shown later, unsteady flow effects found in the present work, may be compared with rotating stall (RS) in compressors. Rotating stall is an unsteady flow phenomenon that involves rotating regions of reversed flow. According to Vagani et al [12], in a centrifugal compressor, the flow distortions that make up rotating stall can appear with multiple lobes, or cells, distributed equidistantly around the impeller passage. The number of cells commonly varies between 1 and 5, with 3-cell stall being the most widely reported. During the operation in rotating stall, the stall cells develop due to the separation of boundary layers within the blade passages. However, 
For submission to the Journal of Mechanical Engineering Science (Part C, Proc. IMechE)

the separated flow does not remain in the same passage as the impeller rotates but rather propagates to an adjacent passage in the impeller. The various passages in the impeller each take turns stalling and then recovering, which causes the stall cells to rotate around the impeller. In general the stall cells in compressors rotate around 50$60 \%$ of the rotor speed $[13,14]$. Recent work by Dodds and Vahdati [15] suggests that unsteady RANS modeling approach is sufficient to capture some important aspects of rotating stall behavior in compressors.

Most of the previous research on the effect of protrusions on disc windage has focused on rig testing and development of empirical correlations. Zimmerman et al., [16] experimentally found that bolts on the disc increase the torque substantially, by a factor of around 2.5. Fully covered bolts, however, only increased the torque above that of a plane disc by $25 \%$. A superimposed radial outflow of throughflow Reynolds number $\mathrm{C}_{\mathrm{w}}=2.6 \times 10^{4}$ increased the windage by around $50 \%$. Millward and Robinson [6] also investigated the influence of protrusions within a rotor-stator cavity. They carried out experiments varying the number of bolts, bolt diameter, pitch, and cross sectional area, attached to either the rotating disc or the stationary casing. They noted that the windage due to bolts located towards the outer radius of the disc was significant, whereas, bolts located towards the inner radius had little effect. Coren [17, 18] measured windage torque associated with a plane disc and a disc with protrusions in a rotor-stator system for a range of rotational and throughflow Reynolds numbers representative of a modern gas turbine engine. Disc core flow velocity measurements and infra-red measurement of disc temperature showed high core flow swirl and significant disc heating when the protrusions were mounted on the rotor. The RMS values of tangential velocity and the negative radial velocity measured inboard of the 
For submission to the Journal of Mechanical Engineering Science (Part C, Proc. IMechE)

protrusions suggest that the flow near the protrusions may be unsteady. Miles [19] investigated windage associated with both stator and rotor mounted bolts, of varying size and shape, as well as cavities in the disc surface. Experiments showed that windage was increased substantially with rotor bolts present, compared with a plane disc, and that windage increased with increasing bolt size. Similar to Coren's observation, Miles reported large fluctuations in tangential velocity inboard of the bolts, using particle image velocimetry (PIV) measurements.

CFD studies on disc cavities with bolts or protrusions have focused primarily on the validation of predicted disc torque by comparison with measured values, assuming the flow is steady and periodic. Moghaddam et al. [20], investigated the effect of bolts on the rotor surface, on moment coefficient and the flow structure, in a shrouded rotor-stator system with superimposed throughflow. Steady CFD simulations were carried out using periodic sector models varying the number of bolts in the range $0 \leq$ $n \leq 60$. As expected, increasing the number of bolts resulted in an increase in the moment coefficient up to 52 bolts. Further increase in the number of bolts resulted in little change in moment coefficient. Moghaddam et al. reported good overall agreement of the moment coefficient calculated using CFD with Coren's [17] experimental data for 3, 9 and 18 bolts cases. Pett et al. [21] carried out steady CFD simulations into rotor-stator configurations for a plane disc, a roughened disc, a roughened stator and stator protrusions. The moment coefficients obtained from CFD were compared to Coren's [17] experiments. For the plane disc and static protrusion cases the agreement with measured torque was within $15 \%$ and $20 \%$ respectively. In a recent paper Noor Mohamed et al. [22] considered both 3D steady CFD modelling of Coren's [17] and Miles' [19] bolt windage experiments and axisymmetric modelling 
For submission to the Journal of Mechanical Engineering Science (Part C, Proc. IMechE)

using a porous zone to represent the bolts. Both methods were shown to agree reasonably well with measurements of rotor moment, but under predicted the core flow swirl and disc surface temperature inboard of the bolts.

The present study extends Noor Mohamed et al.'s research using time resolved CFD to investigate the details of the unsteady flow physics within the cavity. The results reveal large scale unsteady flow structures in the disc cavity. Comparisons are made with the experimental data reported by Coren [17] and Miles [19]. The geometry, CFD model, boundary conditions and the details of various sensitivity studies are described in the next section. Details of the unsteady flow structure and comparison of disc torque, swirl and disc temperature profile from steady and unsteady CFD with experimental data are discussed in section 3, with the main conclusions being summarized in section 4 .

\section{MODEL DEFINITION}

\subsection{TEST CASE CONSIDERED}

Figure 1a shows the general layout of the test rig used for the experiments at the University of Sussex $[17,18,19]$ and selected for this CFD study. A disc of $0.45 \mathrm{~m}$ diameter rotated up to $13000 \mathrm{rpm}$ powered by an electric motor with a gearbox. The disc was surrounded by a cast steel housing. Compressed air was bled to both sides of the casing axially and was also expelled on both sides of the main casing. A torque meter measured the total torque and a correction was made to subtract the contribution due to the driveline friction. Separate driveline friction tests were run to determine the mechanical friction in the bearings and gearbox, as well as aerodynamic friction due to the rotation of the driveshaft. The driveline friction was subtracted from the 
For submission to the Journal of Mechanical Engineering Science (Part C, Proc. IMechE)

measured torque. The resulting net torque is due to windage from the rotation of the disc, with or without features on the rotor surface. In order to minimize axial bearing loading, equal flow and pressure conditions were imposed on both sides of the rotor during the experiments. A labyrinth rim seal installed inside the casing minimized leakage between the two sides of the disc. Rotor bolt tests were conducted using hexagonal bolts of 10,13 and $16 \mathrm{~mm}$ diameter. In addition to the torque measurements, infra red (IR) and laser Doppler anemometry (LDA) instrumentation were used to obtain disc surface temperature and tangential and radial velocity fields in the rotor-stator cavity. Figure $1 \mathrm{~b}$ shows the LDA measurement field in the vicinity of the protrusions on the 'test' side of the disc. Figure 1c shows the bolt orientation with respect to the disc rotation. More information for this test rig and experimental data is given by Coren [17] and Miles [19]. As reported by Miles [19], the uncertainty bars shown for the disc temperature in sections 3 were calculated using the standard technique of root of the sum of the squares (RSS) of each component, of the uncertainty.

\subsection{CFD MODEL}

Steady and unsteady CFD analysis was performed for Coren's [17] low throughflow condition shown in Table 1 with $1816 \mathrm{~mm}$ diameter and $11 \mathrm{~mm}$ high hexagonal bolts fixed at $0.2 \mathrm{~m}$ disc radius $(\mathrm{r} / \mathrm{b}=0.89) .20^{\circ}$ and $120^{\circ} \mathrm{CFD}$ models, with 1 bolt and 6 bolts respectively, and a full $360^{\circ}$ model with 18 bolts were constructed. Similarly, $40^{\circ}-1$ bolt and $120^{\circ}-3$ bolts sector models were built to compare with experimental data corresponding to the 9 bolts case. A single sector $20^{0}$ periodic mesh was copied circumferentially to build the full $360^{\circ}$ CFD model. The $360^{\circ}-18$ bolts model with boundary conditions is shown in Figure 2. Distribution of grid points and 
For submission to the Journal of Mechanical Engineering Science (Part C, Proc. IMechE)

a view of the mesh near the bolts from the same model is shown in Figure 3. The bolts are numbered 1 to 18 in the anti-clockwise direction, with bolt B1 located near the top dead centre. $120^{\circ}-3$ bolts and $120^{\circ}-6$ bolts models were built and meshed separately in ICEM CFD [23]. The steady CFD modelling followed the procedures described by Noor Mohamed et al. [22], and used the k- $\varepsilon$ turbulence model with standard wall functions in the Fluent CFD code [24]. Initial steady CFD simulations were carried out considering both sides of the disc. The moment coefficients from the balance side of the disc were found to be within $5 \%$ of those from the test side. To reduce the computational time, only the cavity on the right-hand side of the disc (test side) was considered for further calculations.

Details of the solver settings and boundary conditions used for the steady CFD are shown in Table 2. The unsteady calculations were started from converged steady state solutions. For unsteady simulations, the spatial discretization was again 2nd order and the solutions were advanced in time using a 2nd order implicit method using the pressure-based coupled implicit solver. This converged faster than the segregated solver [25]. Initial unsteady calculations were carried out by fixing the mass flow at the inlet. Due to large scale unsteadiness within the cavity, a fixed mass flow boundary condition at the inlet resulted in significant total pressure fluctuations at the inlet and an unstable vortex pattern within the cavity. Fixing the total pressure at the inlet was introduced as a more realistic boundary condition. The total pressure specified was adjusted to ensure an average mass flow of $0.125 \mathrm{~kg} / \mathrm{s}$ at inlet corresponding to Coren's test data. 
For submission to the Journal of Mechanical Engineering Science (Part C, Proc. IMechE)

\subsection{SENSITIVITY STUDIES AND CONVERGENCE}

Details of mesh sensitivity studies performed for steady sector models were reported by Noor Mohamed et al [22]. Similar meshes were used here. For the unsteady CFD analysis, a mesh sensitivity test was performed using two different computational meshes for the $120^{\circ}-6$ bolts case. Table 3 shows the number of hexahedral cells in the computational domain for the two meshes and for other unsteady test cases considered. Figure 4 shows non-dimensional swirl fluctuations inboard of the bolt $\mathrm{B} 1$ at $\Theta=10^{0}, \mathrm{r} / \mathrm{b}=0.82, \mathrm{x} / \mathrm{s}=0.4$ (where axial distance $\mathrm{x}$ is measured from the disc surface). The circumferential angle $\Theta$ is defined from $-180^{\circ}$ to $+180^{\circ}$ in the anti-clockwise direction, where $\Theta=0$ is located at the geometric plane of symmetry between bolt $\mathrm{B} 1$ and $\mathrm{B} 18$. Here, and in figures 5 and $6, \mathrm{t}=0$ corresponds to the start of the disc revolution for a stabilised solution and $\mathrm{T}$ is the time for 1 disc revolution. Results are shown for 12 disc rotational periods using the two different meshes. Similar fluctuations were observed for the total temperature inboard of the bolts. The time-averaged swirl and disc-to-inlet temperature difference for the last 5 disc rotations from the fine mesh calculation were found to be within $5 \%$ of time averaged values from the coarse mesh calculation. It was decided to use the mesh with 1.2 million cells in the domain for the final calculations to save computational time.

The $360^{0}-18$ bolts model was built with around 3.2 million cells in the solution domain.

A turbulence model sensitivity study was performed using the two equation standard k- $\varepsilon$ model and a 6 equation Reynolds Stress Model (RSM). The Reynolds stress model showed a slightly weaker and more skewed 3-lobed flow structure within the cavity than the k- $\varepsilon$ model. However, the time averaged total moment coefficient 
For submission to the Journal of Mechanical Engineering Science (Part C, Proc. IMechE)

predicted by RSM was within $5 \%$ of the k- $\varepsilon$ model. The time-averaged values of swirl and total temperature difference from both turbulence models and level of unsteadiness were found to be very similar. To save computational time, it was decided to use the standard $k-\varepsilon$ model for all the final calculations. Standard wall functions with wall $y+$ values in the range of 20 to 200 were used for modelling the near wall flow physics. As the flow involves separation and wake shedding from the bolts the insensitivity to turbulence modelling is perhaps surprising. This may be associated with the strong effects of rotation on the flow dynamics.

Time steps corresponding to $0.10^{\circ}$ and $0.20^{\circ}$ rotor angular displacement at speed $\omega$ were used to investigate the time step sensitivity. The coarser time step corresponding to a $0.20^{\circ}$ rotor revolution resulted in almost identical swirl and temperature fluctuations at the monitor point to the shorter time step. It was decided to use the coarser time step for all further calculations. Similarly, another sensitivity study was performed using 5, 20 and 40 inner iterations at each discrete time point. It was found that 5 inner iterations were sufficient for the inner loop convergence.

The unsteady calculations were assumed to reach convergence when the flow values oscillated at a fixed frequency for at least 5 disc revolutions. This was monitored for several quantities including the moments on the stator and rotor walls, and swirl, total pressure and temperature probes inboard of the bolt $\mathrm{B} 1$ at $\left(\Theta=10^{\circ}\right.$, $\mathrm{r} / \mathrm{b}=0.82, \mathrm{x} / \mathrm{s}=0.4$ from the disc surface). Figure 5 shows instantaneous nondimensional swirl at the monitor point. The $20^{\circ}$ sector URANS calculation shows mild fluctuations. The time-averaged value of the non-dimensional swirl from 7 to 12 disc revolutions of the $20^{\circ}$ sector URANS calculation is nearly the same as the value from steady state CFD. As the sector size is increased to $120^{\circ}$, the non-dimensional 
For submission to the Journal of Mechanical Engineering Science (Part C, Proc. IMechE)

swirl and total temperature difference show higher fluctuations. The time-averaged values of swirl is considerably higher than the values from steady state CFD. This indicates significant unsteadiness within the rotor-stator cavity. The smaller sector model with the imposed periodic boundary condition fails to capture larger scale unsteadiness. It can be seen that the swirl converges to a nearly periodic state within 4 to 5 disc revolutions. However, it was observed that the total temperature continued to increase for up to 25 to 30 disc revolutions.

The convergence of the non-dimensional area averaged disc wall temperature for the $360^{\circ}-18$ bolts and $120^{\circ}-3$ bolts URANS calculations is shown in Figure 6 . The unsteadiness contributes to around $25 \%$ increase in the area averaged disc-to-inlet temperature difference. The time-averaged swirl at the monitoring point for the $360^{\circ}-$ 18 bolts model is found (from the results in figure 5) to be slightly lower than the time-averaged swirl from the $120^{\circ}-6$ bolts model. This could be due to the slightly coarser mesh used for the $360^{\circ}$ model. It was decided to use the $120^{\circ}$ sector model for most of the calculations. A $120^{\circ}-6$ bolts case with around 1.24 million cells in the computational domain took about 8 days to complete 40 disc rotations using 8 nodes with multiprocessors (64 cores) on a PC cluster.

\subsection{RESULTS}

The large scale unsteadiness within the cavity due to wake vortex shedding results in a significant difference in time-averaged swirl and fluid total temperature inboard of the bolts. The unsteady flow dynamics within the cavity from the $360^{\circ}-18$ bolts URANS calculation is discussed in section 3.1. Comparisons of the calculated disc torque, non-dimensional swirl, radial velocity and disc surface temperature with 
For submission to the Journal of Mechanical Engineering Science (Part C, Proc. IMechE)

experimental data are presented in sections 3.2 to 3.4. All the results correspond to the simulated condition of $\mathrm{C}_{\mathrm{w}}=0.3 \times 10^{5}$ and $\lambda=0.09$.

\subsection{UNSTEADY FLOW STRUCTURE}

Comparisons of steady state and instantaneous non-dimensional swirl from steady CFD and URANS calculations from the $360^{\circ}-18$ bolts model are shown in figure 7a. Non-dimensional swirl is given by $\frac{\mathrm{V}_{\theta}}{\mathrm{r} \omega}$, where $V_{\theta}$ is the tangential velocity. In these and other contour plots, the disc rotation is anti-clockwise. The swirl computed from steady CFD appears to be circumferentially uniform at inner radii and periodic over 18 bolts. However, the URANS calculation shows a more circumferentially asymmetric flow pattern with 3 flow cells clearly forming in the inner part of the cavity. These cells rotate at about 50 to $60 \%$ of rotor speed in the stationary frame of reference. It appears that the flow into the cavity splits into 3 streams with the spaces between the streams penetrated by re-circulated fluid that has some angular momentum. Impingement of the three inflow streams on the bolts produces relative strong wakes that impinge at the casing. Weaker wakes, closer aligned to the tangential direction, occur around the bolts inbetween the 3 outflow streams. The unsteady flow may be compared with rotating stall in compressors.

Figure $7 \mathrm{~b}$ shows contours of non-dimensional disc wall temperature difference given by $\left(\frac{T_{w}-T_{i n}}{R_{b}^{2} \omega^{2} / 2 C_{p}}\right)$, where $T_{w}$ is the disc wall temperature and $T_{i n}$ is the inlet temperature. As expected, the unsteady solution shows three cells inboard of the bolts. The URANS calculation also predicts significant disc heating inboard of the bolts, compared to the steady CFD calculation. The circumferential averaged mean 
For submission to the Journal of Mechanical Engineering Science (Part C, Proc. IMechE)

temperature inboard of the bolts from the URANS calculation is much higher than the circumferential averaged value from the steady CFD solution.

After detailed post-processing of several flow variables, a schematic was drawn to help explain the flow dynamics within the cavity for low throughflow conditions and is shown in Figure 8. However it should be remembered that the flow is complex involving 3D and unsteady features that cannot be captured on this diagram.

A comparison of non-dimensional radial velocity inboard of the bolts from steady CFD with instantaneous values from the URANS calculation is shown in figure 9. Here, and in subsequent figures, $\mathrm{t} / \mathrm{T}=0$ corresponds to completion of $40 \mathrm{disc}$ revolutions of the unsteady simulation. Considering these results with those of figure 7, the steady state CFD shows uniform circumferential distribution of the radial throughflow amongst the bolts and the wakes, aligned towards the casing. The time resolved computations show a group of bolt wakes aligned towards the casing and other group shedding tangentially or into the cavity. This creates the 3 celled flow structure within the cavity.

More details of the unsteady flow dynamics are illustrated with the help of contours of instantaneous flow angle in figure 10a. Here flow angle is defined as the angle the resultant of the tangential and radial velocity components make with the radial line, as shown in figure $10 \mathrm{~b}$. The flow angle $\alpha$ will be $90^{\circ}$ for flow with a zero or negligible radial velocity component. Circumferential variation of instantaneous flow angle at $\mathrm{x} / \mathrm{s}=0.4, \mathrm{r} / \mathrm{b}=0.82$ inboard of the bolts for five different times spanning about 0.42 of a disc revolution is shown in figure $10 \mathrm{c}$ for a $90^{\circ}$ sector. Again $\mathrm{t} / \mathrm{T}=0$ corresponds to completion of 40 disc revolutions of the unsteady simulation. The steady flow CFD solution is also shown. For the steady CFD case the variation in 
For submission to the Journal of Mechanical Engineering Science (Part C, Proc. IMechE)

flow angle is the same around each bolt and is approximately $+/-5^{\circ}$ from the mean $90^{\circ}$ flow angle. URANS calculations show $+/-15^{0}$ variation from the mean. The yellow contours inboard of the bolts in the figure 10a show higher flow angles, which occur when the bolt wakes are pushed towards the inner radius of the disc cavity. From $\mathrm{t} / \mathrm{T}=0.01$ to 0.29 , the region of high flow angle moves from bolt 3 (B3) to bolt 1 (B1) in the clockwise direction. The red dotted line in figure 10c further indicates how the flow cells move around the cavity, corresponding to a rotation of the flow structure in the opposite direction to the disc rotation at $40 \%$ of the disc speed (in the rotating frame). The peak flow angle is closer to bolt $\mathrm{B} 3$ at $\mathrm{t} / \mathrm{T}=0.01$. It moves around half a bolt pitch for a flow time corresponding to 0.07 times the disc rotation period, showing a clear peak between bolt B3 and B2 at $\mathrm{t} / \mathrm{T}=0.08$. However, at $\mathrm{t} / \mathrm{T}=0.36$, the flow angle line plot does not show a peak in-between bolt B1 and B18 as might be expected. This indicates complex flow interactions. At $\mathrm{t} / \mathrm{T}=0.43$, as expected, the flow angle line plot shows a clear peak closer to bolt B18.

Rotating stall in compressors is associated with flow separation in a blade passage ( or group of blade passages) deflecting the flow so that upstream blades are likely to stall and downstream blades are likely to un-stall. Figure 10a suggests a similar mechanism for the present flow, with the inflow regions deflecting the outflow which in turn alters the angle of impingement of the flow on the bolts and the interaction with the shroud.

The unsteady pressure was recorded from numerical probes inboard and in the wake of the bolts inside the rotor-stator cavity in the rotating frame of reference. Spectral analysis of the pressure signal was carried out using Discrete Fourier Transforms (DFT) of the recorded static pressure signals. Figure 11 shows results of 
For submission to the Journal of Mechanical Engineering Science (Part C, Proc. IMechE)

the DFT for the pressure fluctuations in the cavity at the point $\Theta=10^{0}, \mathrm{r} / \mathrm{b}=0.82, \mathrm{x} / \mathrm{s}=0.4$ from the disc surface. This shows, peak pressure fluctuations corresponding to a frequency of about 1.5 to 1.6 times disc speed for all the three cases. This corresponds to the rotating three-lobed structure within the cavity. The peak pressure fluctuation is $\sim 3.4 \mathrm{kPa}$ for the $120^{\circ}-6$ bolts case, $2.9 \mathrm{kPa}$ for the $360^{\circ}-18$ bolts case and $1.9 \mathrm{kPa}$ for the $120^{0}-3$ bolts case. The 3 -lobed rotating structures rotate circumferentially with $\sim 50$ to $60 \%$ of the rotor disc speed in the stationary frame. Weaker, higher frequency fluctuations are attributed to vortex shedding from the bolts. This is supported by estimates of the shedding frequency using the average relative velocity upstream of the bolts and by assuming a Strouhal number of 0.2 , although this calculation is sensitive to the relative "free stream" velocity assumed.

\subsection{DISC AND BOLT TORQUE}

The Reynolds number based on bolt diameter and average relative velocity at a line $\mathrm{x} / \mathrm{s}=0.25$ from disc surface on the geometric plane of symmetry between bolt B1 and B2 is shown in table 4. The Reynolds number falls in the range between 8.29E+4 to $1.96 \mathrm{E}+5$. Comparison with the flow past a circular cylinder with Reynolds number based on free stream velocity, suggest that the flow regime is sub-critical, so that regular vortex shedding characterised by turbulent vortex street might be expected [26]. The Reynolds number based on upstream relative velocity from the steady state analysis is $1.4 \mathrm{E}+5$ which is also sub-critical.

Table 4 also shows the variation of circumferential and radial drag coefficient on bolt $\mathrm{B} 1$, for tht time period $\mathrm{t} / \mathrm{T}=0.01$ to $\mathrm{t} / \mathrm{T}=0.43$. Here the drag components are calculated using the following expressions, 
For submission to the Journal of Mechanical Engineering Science (Part C, Proc. IMechE)

$$
\mathrm{C}_{\mathrm{d} \Theta}=\frac{-\mathrm{F}_{\mathrm{d} \theta}}{1 / 2 \rho \omega^{2} \mathrm{~b}^{4}} \text { and } \mathrm{C}_{\mathrm{dr}}=\frac{-\mathrm{F}_{\mathrm{dr}}}{1 / 2 \rho \omega^{2} \mathrm{~b}^{4}}
$$

where $F_{d \theta}$ is the total force on a bolt in the circumferential direction and $F_{d r}$ is the total radial force. Over the disc rotation period considered here, the circumferential drag coefficient varies from $1.86 \mathrm{E}-4$ to $7.39 \mathrm{E}-4$ and the radial drag coefficient varies from 1.22E-4 to 3.81E-4. The circumferential and radial drag coefficients from steady CFD are 3.69E-4 and 2.51E-4 respectively. The large variation of drag coefficients can be explained with the help of static pressure distributions over the bolt. Referring to figure 12 , the circumferential drag force coefficient is closer to the steady solution value at $\mathrm{t} / \mathrm{T}=0.01$, lowest in magnitude at $\mathrm{t} / \mathrm{T}=0.15$, and highest in magnitude at $\mathrm{t} / \mathrm{T}=0.43$. Here the bolt circumferential angle $\Theta^{\prime}$ is defined clockwise from the leading edge of the hexagonal bolt. The low circumferential drag of bolt $\mathrm{B} 1$ at $\mathrm{t} / \mathrm{T}=0.15$ corresponds to the wake of the bolt B2 being more aligned towards bolt B1 and the reduced dynamic pressure within the wake. This can also be interpretted as the shielding effect or wake interference effects of bolts [27]. The average relative velocity upstream of the bolt is lowest at this instance. The drag coefficient is highest at $\mathrm{t} / \mathrm{T}=0.43$, where the relative velocity upstream of the bolt is highest. As the wake moves towards the casing, fluid from the rotating core impinges the hexagonal bolt. Static pressure plots indicate a stagnation point at around $340^{\circ}$, at times where the bolt wake is more aligned towards the casing. The fluid from the rotating core impinges on the two upstream faces of the bolt with acceleration towards the downstream edges of these faces and flow seperation at the edges indicated by the dips in pressure at $60^{\circ}$ and $300^{\circ}$. Static pressure from the steady CFD corresponds roughly to an average of the instantaneous values from the URANS calculation. 
For submission to the Journal of Mechanical Engineering Science (Part C, Proc. IMechE)

Figure 13 shows instantaneous contributions to moment coefficient of individual bolts from a URANS calculation and the steady CFD solution for the $360^{\circ}-18$ bolts case. The torque contribution from bolts calculated from the unsteady and steady solution is nearly the same and the average contribution to the moment coefficient is $\sim 0.00041$ per bolt. However, the URANS calculation shows a significant variation between the bolts. The individual bolt contribution to $\mathrm{C}_{\mathrm{m}}$ varies from 0.00016 to 0.00065. Figure 14 shows the comparison of instantaneous values of the total moment coefficient from the bolts and disc for both sides with steady CFD values and with the moment coefficient from Coren's [17] experiment. The $C_{m}$ calculated from the steady and unsteady CFD is slightly higher than the $C_{m}$ from the measured disc torque. However, this variation is within the experimental uncertainty [22].

\subsection{TANGENTIAL AND RADIAL VELOCITY}

Figure 15 shows instantaneous non-dimensional swirl and radial velocity at three different monitor points inboard of the bolts. The highest fluctuations in nondimensional swirl occur at $\mathrm{r} / \mathrm{b}=0.82$ with the magnitude of fluctuations reducing with distance from the bolts. The radial velocity, however, shows the reverse trend, with highest fluctuations at a location $\mathrm{r} / \mathrm{b}=0.64$ and lower velocity fluctuations at the location close to the bolts.

Figures 16 and 17 show comparisons of non-dimensional swirl and radial velocity inboard of the bolts at axial location $\mathrm{x} / \mathrm{s}=0.4$ from steady CFD, circumferentialaveraged values from URANS calculations, and the RMS values from Coren's [17] experimental data for the 18 bolts case. The bars for the experimental data represent measured physical fluctuations in the fluid motion, not uncertainty in the measuring equipment. The bars shown in the URANS data give the maximum and minimum 
For submission to the Journal of Mechanical Engineering Science (Part C, Proc. IMechE)

values of the circumferential variation. Steady CFD clearly under-predicts the swirl radially inboard of the hexagonal bolt compared to experimental data. The circumferentially averaged URANS data shows significantly better agreement with the measured swirl velocity than the steady CFD. However, the average nondimensional swirl is lower than the measured RMS value by 0.13 at $r / b=0.82$. The URANS calculation agrees better with experimental data at $\mathrm{r} / \mathrm{b}=0.64$. The average radial velocity at the monitor points is close to zero and steady CFD agrees well with circumferentially averaged URANS data showing slight variation with the experimental data. Qualitative comparisons can be made between the length of the bars shown on the experimental data and URANS calculation. Generally the levels of unsteadiness are similar. However, since details of the experimental method and calculation are not reported, no further conclusions should be drawn from this comparison.

Figure 18 shows the comparison of non-dimensional swirl inboard of the bolts at axial location $\mathrm{x} / \mathrm{s}=0.4$ for the 9 bolts case. Steady CFD again under predicts nondimensional swirl at all radii compared to experimental data. The circumferentialaveraged value from the URANS calculation agrees well with the RMS value from the experiment at $\mathrm{r} / \mathrm{b}=0.82$ and $\mathrm{r} / \mathrm{b}=0.75$. At $\mathrm{r} / \mathrm{b}=0.64$ the URANS calculation is $\sim 0.06$ lower than the measured value. The levels of unsteadiness in the URANS calculation and the measurements are similar.

\subsection{ROTOR TEMPERATURE}

Coren's [17] experimental data showed high core flow swirl and significant disc heating at all radii for the rotationally dominated conditions considered here. Figure 19 shows the non-dimensional adiabatic disc-to-inlet air temperature difference on the 
For submission to the Journal of Mechanical Engineering Science (Part C, Proc. IMechE)

rotor surface for the 18 and 9 bolts cases from steady CFD, circumferential averaged URANS data and experimental data. After 30 disc revolutions, the time-averaged value from URANS calculation at a circumferential location is found to be nearly the same as the circumferential average value at a time instance. Steady CFD and the URANS calculations predict similar air outlet temperatures. However steady CFD under-predicts the disc temperature inboard of the bolts. The difference in nondimensional wall temperature between the steady CFD and measurement corresponds to an adiabatic wall temperature difference as high as 20K. URANS calculations capture the unsteady fluctuations and predict disc temperature profiles comparable with the experimental data for both 9 and 18 bolts cases. The difference in nondimensional wall temperature between the URANS and measurement inboard of the bolts at $\mathrm{r} / \mathrm{b}=0.69$, corresponds to an adiabatic wall temperature difference of $\sim 3 \mathrm{~K}$ for the 18 bolts case and $\sim 1 \mathrm{~K}$ for the 9 bolts case. Coren's test rig includes a labyrinth rim seal installed inside the casing to minimize the leakage between the test and balance sides. To reduce the computational time, the labyrinth seal was omitted from the computational domain. The difference in adiabatic wall temperature between steady $\mathrm{CFD} / \mathrm{URANS}$ calculation and the experimental data at higher radii $\mathrm{r} / \mathrm{b}=0.89$ and 0.94 could be due to the additional windage heating of the rotor from labyrinth seal.

\section{0 CONCLUSIONS}

Unsteady CFD modelling of a rotor-stator disc cavity with bolt protrusions using $120^{\circ}$ sector and $360^{\circ}$ models has been performed and has given new insight into the flow in such systems. Comparisons were made with experimental data and with smaller sector steady and unsteady CFD models. Time-resolved large sector CFD 
For submission to the Journal of Mechanical Engineering Science (Part C, Proc. IMechE)

calculations revealed complex wake interactions and unsteadiness within the disc cavity at low throughflow conditions. The conclusions can be summarized as follows:

1. The URANS calculations show complex wake vortex shedding and unsteady flow within the cavity. The interaction of the wake vortices from bolts and the radial throughflow results in a three-lobed rotating structure within the core of the rotorstator cavity. These structures are sensitive to the cavity inlet boundary condition.

2. Spectral analysis of the URANS solutions confirms observations of unsteady flow within the disc cavity. Analysis of the temporal pressure signal shows high amplitude pressure fluctuations corresponding to a frequency of about 1.5 to 1.6 times disc rotation in the rotating frame for all the three cases. These pressure fluctuations correspond to the 3 lobed flow structures rotating at about half disc speed in the stationary reference frame. Weaker, higher frequency fluctuations are also observed, corresponding to vortex shedding from the bolts. While there is no direct experimental confirmation of 3 lobed structures, the level of unsteadiness predicted is similar to that indicated in measurements. The effect of geometry and flow conditions on flow structure is the subject of a further study [28].

3. Steady CFD significantly under-predicts the core flow swirl and the disc temperature inboard of the bolts for the rotationally dominated flow cases considered. Circumferential-averaged values of non-dimensional swirl and disc surface temperature from URANS calculations agree much better with the experimental data. Both steady and URANS calculations predict similar air temperature at the outlet and agree reasonably well with rotor torque measurements. 
For submission to the Journal of Mechanical Engineering Science (Part C, Proc.

IMechE)

\section{ACKNOWLEDGMENTS}

The authors wish to express their appreciation to Dr. Daniel Coren for answering many queries related to the Sussex bolt windage test. The authors also express gratitude to Rolls-Royce plc and the Clean Sky Joint Technology Initiative for providing financial support for this work.

\section{NOMENCLATURE}

b Disc outer radius, $m$

$\mathrm{C}_{\mathrm{d} \theta} \quad$ Circumferential drag coefficient $\left(=\frac{\mathrm{F}_{\mathrm{d} \theta}}{1 / 2 \rho \omega^{2} b^{4}}\right)$

$\mathrm{C}_{\mathrm{dr}} \quad$ Radial drag coefficient $\left(=\frac{\mathrm{F}_{\mathrm{r}}}{1 / 2 \rho \omega^{2} b^{4}}\right)$

$\mathrm{C}_{\mathrm{m}} \quad$ Moment coefficient $\left(=\frac{M}{1 / 2 \rho \omega^{2} b^{5}}\right.$ for both sides of the disc $)$

$\mathrm{Cp} \quad$ Specific heat at constant pressure, $\mathrm{J} / \mathrm{kg} \mathrm{K}$

$\mathrm{C}_{\mathrm{w}} \quad$ Throughflow Reynolds number $\left(=\frac{\dot{m}}{\mu b}\right)$

D Diameter of bolts (measured across flats), $\mathrm{m}$

$\mathrm{F}_{\mathrm{d} \theta} \quad$ Circumferential drag force $(\mathrm{N})$

$\mathrm{F}_{\mathrm{dr}} \quad$ Radial drag force $(\mathrm{N})$

f Frequency of rotation, $\mathrm{Hz}$

$\mathrm{f}_{\mathrm{d}} \quad$ Disc rotational frequency, $\mathrm{Hz}$

G Gap ratio $(=s / b)$

$k_{\text {air }} \quad$ Thermal conductivity of air, W/(m K)

$l \quad$ near-wall turbulence model length scale

M Torque on both sides of the disc, Nm

$\dot{\mathrm{m}} \quad$ Mass flow rate, $\mathrm{kg} / \mathrm{s}$

$\mathrm{N} \quad$ Rotational speed, rev/min

$\mathrm{Nu} \quad$ Nusselt number

n Number of bolts

$\mathrm{P}_{\mathrm{s}} \quad$ Static pressure, $\mathrm{Pa}$ 
For submission to the Journal of Mechanical Engineering Science (Part C, Proc. IMechE)

$\mathrm{P}_{\text {in }} \quad$ Inlet total pressure, bars

$q_{w} \quad$ Wall heat flux, W/m ${ }^{2}$

$\mathrm{R}_{\mathrm{b}} \quad$ Radial location of the bolts, $\mathrm{m}$

Re Reynolds number $\left(=\frac{\rho \mathrm{V}_{\text {rel-avg } \mathrm{D}}}{\mu}\right)$

$\operatorname{Re}_{\varnothing} \quad$ Rotational Reynolds number $\left(=\frac{\rho \omega b^{2}}{\mu}\right)$

$\mathrm{r}$ Local radius, radial direction, $\mathrm{m}$

s Disc-to-stator axial spacing, $\mathrm{m}$

$\mathrm{t}$ Flow time (from start of current period), $\mathrm{s}$

$\mathrm{T}$ Time for one disc revolution, $\mathrm{s}$

$\mathrm{T}_{\text {in }} \quad$ Inlet total temperature, $\mathrm{K}$

$\mathrm{T}_{\mathrm{t}} \quad$ Fluid total temperature, $\mathrm{K}$

$\mathrm{T}_{\mathrm{w}} \quad$ Wall static temperature, $\mathrm{K}$

$u_{f} \quad$ Friction velocity $\left(=\sqrt{\tau_{w} / \rho}\right), \mathrm{m} / \mathrm{s}$

$\mathrm{V}_{\theta} \quad$ Tangential velocity, $\mathrm{m}$

$\mathrm{V}_{\text {rel-avg }}$ Average relative free stream velocity, $\mathrm{m} / \mathrm{s}$

$\mathrm{V}_{\mathrm{r}} \quad$ Radial velocity, $\mathrm{m}$

$\mathrm{V}_{\theta, \mathrm{r}} \quad$ Resultant of tangential and radial velocity, $\mathrm{m} / \mathrm{s}$

$\mathrm{y}^{\prime} \quad$ Normal distance from the wall, $\mathrm{m}$

$\mathrm{x}, \mathrm{y}, \mathrm{z} \quad$ Cartesian co-ordinates

$\mathrm{y}+\quad$ non-dimensional wall distance $\left(=y^{\prime} u_{f} / \mu\right)$

\section{Greek symbols}

$\Delta \mathrm{T}_{\mathrm{t}-\mathrm{non}} \quad$ Non-dimensional total temperature difference $\left(\frac{\mathrm{T}_{\mathrm{t}}-\mathrm{T}_{\text {in }}}{\mathrm{R}_{\mathrm{b}}^{2} \omega^{2} / 2 \mathrm{C}_{\mathrm{p}}}\right)$

$\Delta \mathrm{T}_{\mathrm{w}-\mathrm{non}}$ Non-dimensional wall static temperature difference $\left(\frac{\mathrm{T}_{\mathrm{w}}-\mathrm{T}_{\mathrm{in}}}{\mathrm{R}_{\mathrm{b}}^{2} \omega^{2} / 2 \mathrm{C}_{\mathrm{p}}}\right)$

$\Delta \mathrm{T}_{\text {wavg- }} \quad$ Non-dimensional area averaged wall static temperature difference

non $\quad\left(\frac{T_{w a v g}-T_{i n}}{R_{b}^{2} \omega^{2} / 2 C_{p}}\right)$

$\varepsilon \quad$ Turbulence dissipation rate, $\mathrm{m}^{2} / \mathrm{s}^{3}$

k Turbulent kinetic energy, $\mathrm{m}^{2} / \mathrm{s}^{2}$ 
For submission to the Journal of Mechanical Engineering Science (Part C, Proc. IMechE)

$\lambda \quad$ Throughflow parameter $=\frac{C_{w}}{R e_{\varnothing}{ }^{0.8}}$

$\mu \quad$ Dynamic viscosity, $\mathrm{kg} / \mathrm{m} . \mathrm{s}$

$\omega \quad$ Disc speed, $\mathrm{rad} / \mathrm{s}$

$\rho \quad$ Fluid density, $\mathrm{kg} / \mathrm{m}^{3}$

$\alpha \quad$ Flow angle, degree

$\Theta \quad$ Circumferential angle, degree

$\tau_{w} \quad$ Wall shear stress, $\mathrm{Pa}$

\section{Abbreviations}

CFD Computational Fluid Dynamics

DFT Discrete Fourier Transform

IR Infra Red

LDA Laser Doppler Anemometry

PIV Particle Image Velocimetry

RMS Root Mean Square

RS Rotating Stall

RSS Root of Sum of Squares

RSM Reynolds Stress Model

TKE Turbulent Kinetic Energy

URANS Unsteady Reynolds averaged Navier-Stokes equations

\section{REFERENCES}

1. Daily, J. W. and Nece, R. E., 1960 "Chamber dimension effects on induced flow and frictional resistance of enclosed rotating discs", J. Basic Eng., Vol. 82, 217232.

2. Daily, J.W., Ernst, W.D., and Asbedian, V.V., 1964 "Enclosed rotating disks with superposed through-flow", Technical Report 64, Hydrodynamics Laboratory, M.I.T, Cambridge, MA. 
For submission to the Journal of Mechanical Engineering Science (Part C, Proc. IMechE)

3. Von Kármán, T., 1921 "Uber laminare und turbulente Reibung", Z.Angew. Math. Mech., vol.1, pp.233-252.

4. Chew, J.W., and Vaughan, C.M., 1988 "Numerical predictions for the flow induced by an enclosed rotating disc", ASME Paper 88-GT-127.

5. Virr G. P., Chew J. W., Coupland J.,1994 "Application of Computational Fluid Dynamics to Turbine Disk Cavities" J. Turbomach. 116(4), 701-708.

6. Millward, J. A. and Robinson, P. H., 1989 "Experimental Investigation into the Effects of Rotating and Static Bolts on Both Windage Heating and Local Heat Transfer Coefficients in a Rotor-Stator Cavity", Gas turbine and aero-engine congress and exposition paper, 89-GT-196.

7. Greenspan, H.P., "The theory of rotating fluids", Cambridge, 1968.

8. Cao, C., Chew, J.W., Millington, P.R. and Hogg, S.I. 2004 "Interaction of Rim Seal and Annulus Flow in an Axial Flow Turbine", J. of Eng. for Gas Turbines and Power, 126:786-793.

9. Jakoby, R., Zierer, T., Lindblad, K., Larssson, J., deVito, L., Bohn, D. E., Funcke, J., and Decker, A., 2004, "Numerical Simulation of the Unsteady Flow Field in an Axial Gas Turbine Rim Seal Configuration,” ASME Paper No. GT2004-53829.

10. Czarny, O., Iacovides, H., and Launder, B. E., 2002 "Processing Vortex Structures in Turbulent Flow Within Rotor-Stator Disc Cavities," Flow, Turbulence and Combustion, 69(1), pp. 51-61.

11. Craft, T., Iacovides, H., Launder, B., and Zacharos, A., 2008 "Some SwirlingFlow Challenges for Turbulent CFD,” Flow, Turbul. Combust., 80(4), pp. 419434. 
For submission to the Journal of Mechanical Engineering Science (Part C, Proc. IMechE)

12. Vagani, M., Engeda, A., and Cave, M, J., 2013 "Prediction of impeller rotating stall onset using numerical simulations of a centrifugal compressor. Part 1: Detection of rotating stall using fixed-flow transient simulations" Proc IMechE Part A: J Power and Energy.

13. Arnulfi, G. L., Micheli, D., and Pinamonti, P., 1996 “Experimental Investigation on Rotating Stall in a Centrifugal Blower With Two and Four Stages and Vaneless Diffusers,' ASME Paper No. 96-GT-171.

14. Saxer-Felici, H. M., Saxer, A., Inderbitzin, A., and Gyarmathy, G., 1999 "Prediction and Measurement of Rotating Stall Cells in an Axial Compressor," ASME. J. Turbomachinery, Vol. 121, pp. 365-375.

15. Dodds, J., Vahdati, M., 2015 "Rotating Stall Observations in a High Speed Compressor-Part II: Numerical Study", ASME. J. Turbomachinery.

16. Zimmerman, H., Firsching, A., Dibelius, G. H., and Ziemann, M., 1986 "Friction Losses and Flow Distribution for Rotating Discs with Shielded and Protruding Bolts", ASME international gas turbine conference paper 86-GT-158.

17. Coren, D., 2007 "Windage due to Protrusions in Rotor-Stator Systems", ThermoFluid Mechanics Research Centre, University of Sussex, D. Phil Thesis.

18. Coren, D.D., Childs, P.R.N. and Long, C.A., 2009 "Windage sources in smoothwalled rotating disc systems", Proc IMechE,Part C: J Mechanical Engineering Science; 233:873-888.

19. Miles, A., 2011 "An Experimental Study of Windage due to Rotating and Static Bolts in an Enclosed Rotor-Stator System", Thermo-Fluid Mechanics Research Centre, University of Sussex, D. Phil Thesis. 
For submission to the Journal of Mechanical Engineering Science (Part C, Proc. IMechE)

20. Moghaddam, E. R., Long, C. A. and Sayma, A., 2013 "A Numerical Investigation of Moment Coefficient and Flow Structure in a Rotor-Stator Cavity with Rotor Mounted Bolts", Proceedings of the Institution of Mechanical Engineers, Part A: Journal of Power and Energy.

21. Pett, A., Coren, D. and Childs, P., 2007 "Model Validation for a Shrouded RotorStator System with Superposed Cooling and Static Protuberances", Proceedings of ASME Turbo Expo 2007 conference paper, GT2007-27744.

22. Noor Mohamed, S., Chew, J.W. and Hills, N.J., 2015 "Simplified protrusion drag and heat transfer modelling of bolts on a rotating disc", ASME Paper No. GT2015-43501.

23. ICEMCFD manual, ICEMCFD 14 User manual. Ansys Inc. 2011.

24. ANSYS FLUENT 14.0 User's Guide, October 2012, Ansys Inc.

25. Colin Young, "An Evaluation of the Pressure-Based Coupled Solver in ANSYS FLUENT-v12" ANSYS Regional Conference Proceedings - June 2013.

26. Lienhard J.H., 1966 "Synopsis of lift, drag and vortex frequency data for rigid circular cylinders", Washington State University, College of Engineering, Research Division Bulletin 300.

27. Hoerner, S. F., 1965 "Fluid-dynamic drag", Hoerner Fluid Dynamics.

28. Noor Mohamed, S., Chew, J.W. and Hills, N.J., 2016 "Effect of bolts on flow and heat transfer in a rotor-stator disc cavity", ASME Paper No. GT2016-56470. 
For submission to the Journal of Mechanical Engineering Science (Part C, Proc. IMechE)

Table 1. Simulated flow conditions

\begin{tabular}{|c|c|c|c|c|c|c|}
\hline$\dot{\mathrm{m}}(\mathrm{kg} / \mathrm{s})$ & $\mathrm{Re}_{\varphi}$ & $\mathrm{C}_{\mathrm{w}}$ & $\lambda$ & $\omega(\mathrm{rad} / \mathrm{s})$ & $\mathrm{P}_{\text {in }}(\mathrm{bar})$ & $\mathrm{T}_{\text {in }}(\mathrm{K})$ \\
\hline 0.125 & $7.4 \times 10^{6}$ & $0.3 \times 10^{5}$ & 0.09 & 921.53 & 3 & 295 \\
\hline
\end{tabular}

Table 2. Solver settings and boundary conditions used for the steady flow analysis

\begin{tabular}{|c|c|}
\hline Solver & Segregated, implicit, steady state solver with absolute velocity formulation. \\
\hline $\begin{array}{l}\text { Boundary } \\
\text { Conditions }\end{array}$ & $\begin{array}{l}\text { - Disc: no-slip, adiabatic, rotating at speed } \omega \text { as defined by experimental data being } \\
\text { modeled. } \\
\text { - Casing: no-slip, adiabatic, stationary. } \\
\text { - Inlet(s): mass flow and total temperature set from experimental data. Zero swirl, } \\
5 \% \text { turbulence intensity and length scale equal to } 0.07 \mathrm{x} \text { hydraulic diameter. } \\
\text { - Outlet(s): constant pressure outlet, static pressure set to } 0 \text { Pa relative to the } \\
\text { operating condition. }\end{array}$ \\
\hline Fluid & Air modeled as an ideal gas. \\
\hline $\begin{array}{l}\text { Solver } \\
\text { Control }\end{array}$ & $\begin{array}{l}\text { 2nd order discretization set on all variables including energy equation, PRESTO for } \\
\text { the pressure solution. }\end{array}$ \\
\hline
\end{tabular}

Table 3. Number of cells in the computational domain for all unsteady test cases

\begin{tabular}{|c|c|}
\hline Case \# & Number of cells (million) \\
\hline $120^{\circ}-6$ bolts - Mesh1 & 1.2 \\
\hline $120^{\circ}-6$ bolts - Mesh2 & 4 \\
\hline $120^{0}-3$ bolts & 1.2 \\
\hline $360^{\circ}-18$ bolts & 3.2 \\
\hline
\end{tabular}

Table 4. Bolt drag coefficients and Reynolds number based on average relative velocity at a line $\mathrm{x} / \mathrm{s}=0.25$ from disc surface on the geometric periodic plane between bolt B1 and B2 after 40 disc rotations $-360^{\circ}-18$ bolts case

\begin{tabular}{|c|c|c|c|c|}
\hline Case \# & $\mathbf{V}_{\text {rel-avg }}(\mathbf{m} / \mathbf{s})$ & $\mathbf{R e}$ & $\mathbf{C}_{\mathbf{d} \boldsymbol{\theta}}$ & $\mathbf{C}_{\mathbf{d r}}$ \\
\hline Steady RANS & 53.5 & $1.40 \mathrm{E}+05$ & $3.69 \mathrm{E}-4$ & $2.51 \mathrm{E}-4$ \\
\hline URANS t/T 0.01 & 43.5 & $1.14 \mathrm{E}+05$ & $3.11 \mathrm{E}-4$ & $2.07 \mathrm{E}-4$ \\
\hline URANS t/T 0.15 & 31.6 & $8.29 \mathrm{E}+04$ & $1.86 \mathrm{E}-4$ & $2.95 \mathrm{E}-4$ \\
\hline URANS t/T 0.22 & 33.2 & $8.69 \mathrm{E}+04$ & $2.13 \mathrm{E}-4$ & $3.81 \mathrm{E}-4$ \\
\hline URANS t/T 0.36 & 71.4 & $1.87 \mathrm{E}+05$ & $5.08 \mathrm{E}-4$ & $1.22 \mathrm{E}-4$ \\
\hline URANS t/T 0.43 & 75.0 & $1.96 \mathrm{E}+05$ & $7.39 \mathrm{E}-4$ & $2.01 \mathrm{E}-4$ \\
\hline
\end{tabular}


For submission to the Journal of Mechanical Engineering Science (Part C, Proc. IMechE)

(a)

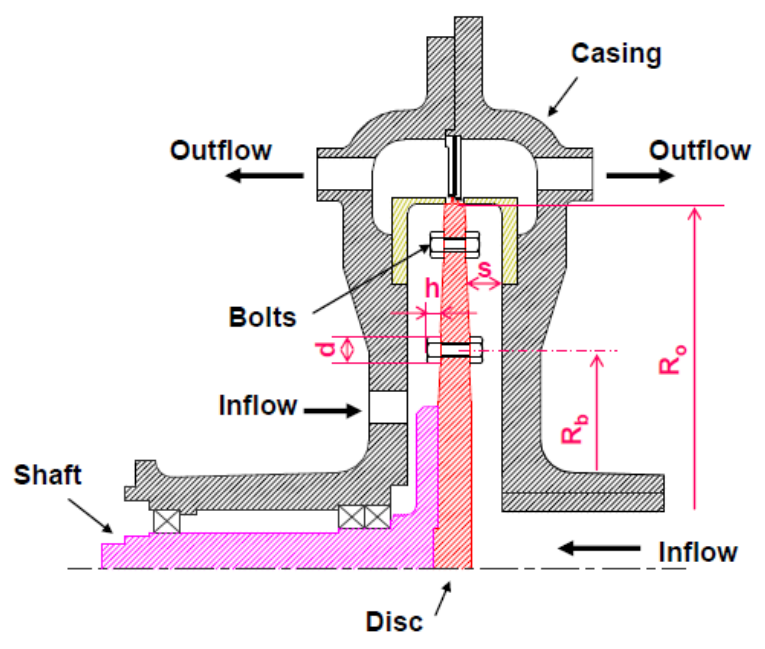

(b)

(c)

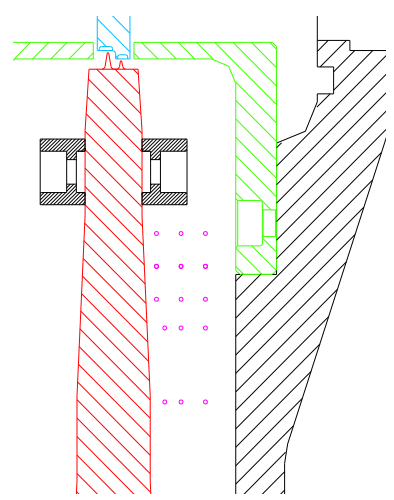

Circumferential direction

Figure 1. (a) Bolt Windage Rig-University of Sussex (b) LDA measurement location and (c) bolt orientation with respect to direction of rotation (Coren [17])
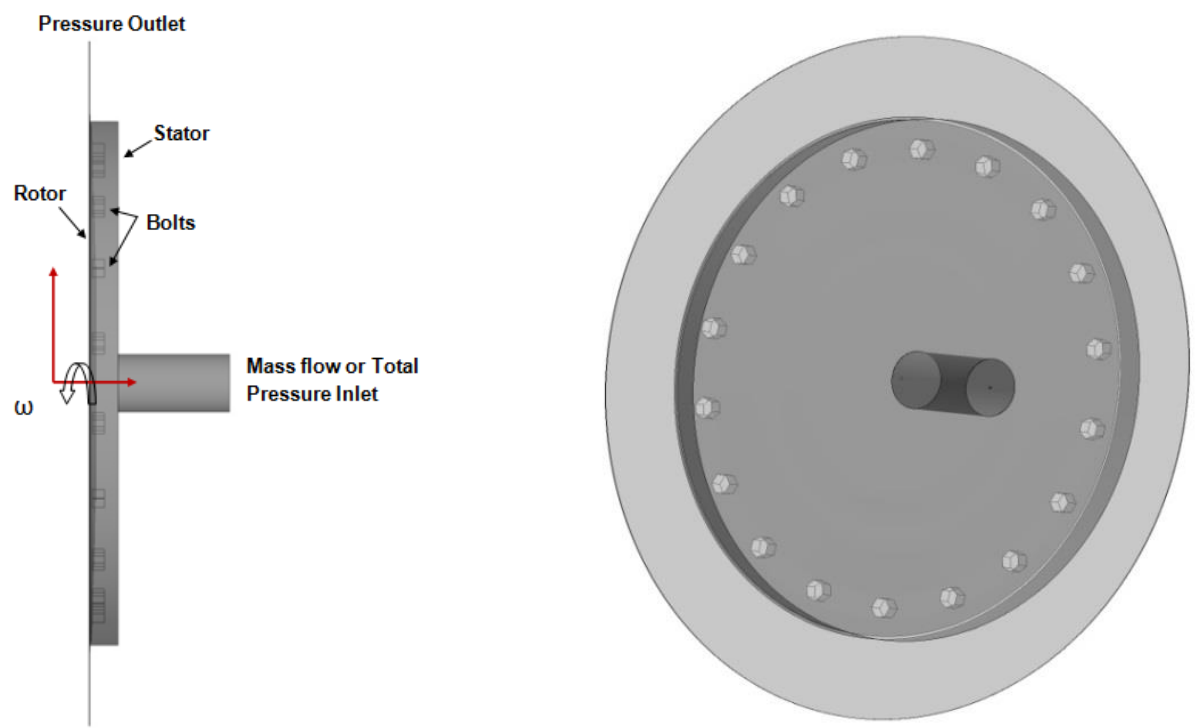

Figure $2.360^{\circ}-18$ bolts domain with boundary conditions 
For submission to the Journal of Mechanical Engineering Science (Part C, Proc. IMechE)

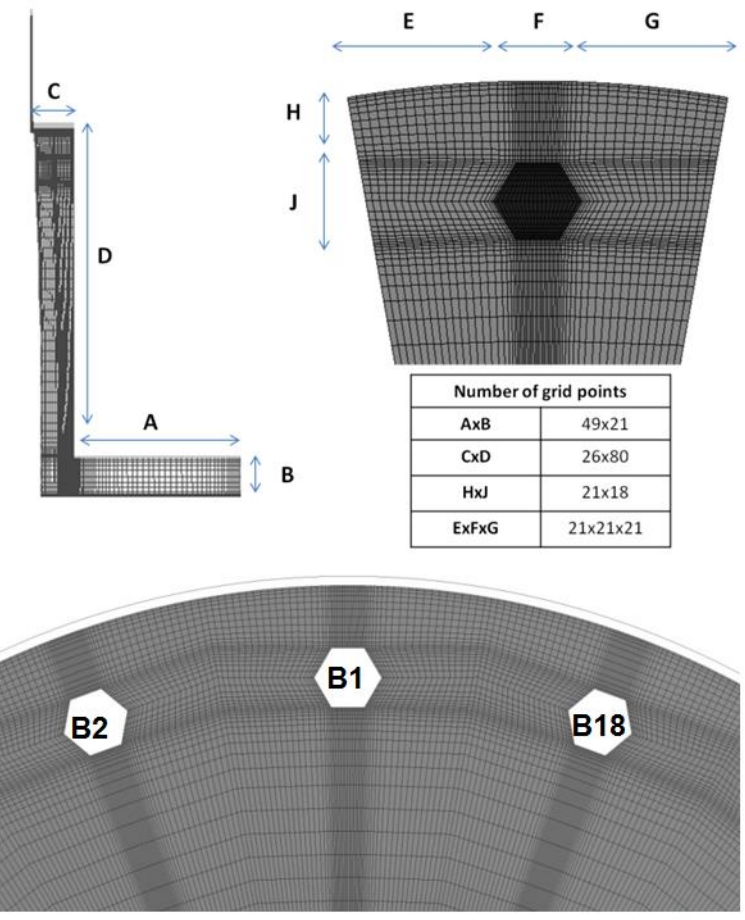

Figure 3. Distribution of grid points and view of mesh near the bolts for $360^{\circ}-18$ bolts model

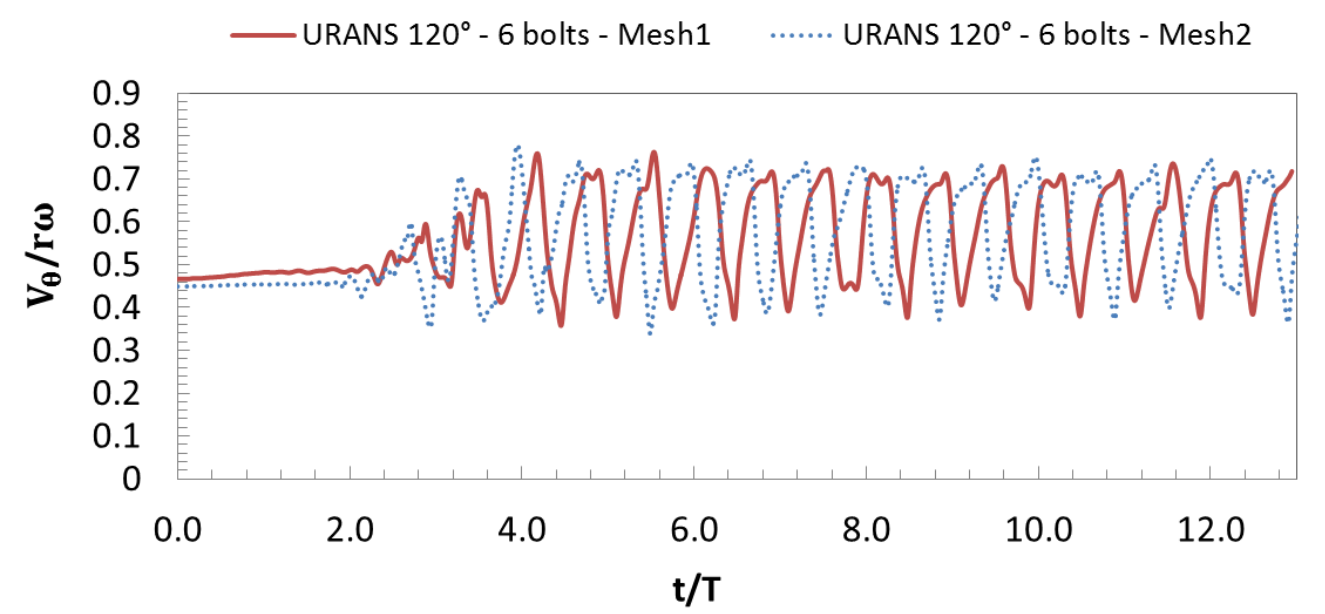

Figure 4. Instantaneous non-dimensional swirl inboard of bolt $\mathrm{B} 1\left(\Theta=10^{0}, \mathrm{r} / \mathrm{b}=0.82, \mathrm{x} / \mathrm{s}=0.4\right.$ from disc surface) -URANS $120^{\circ}$ - 6 bolts model using two different computational meshes 
For submission to the Journal of Mechanical Engineering Science (Part C, Proc.

IMechE)

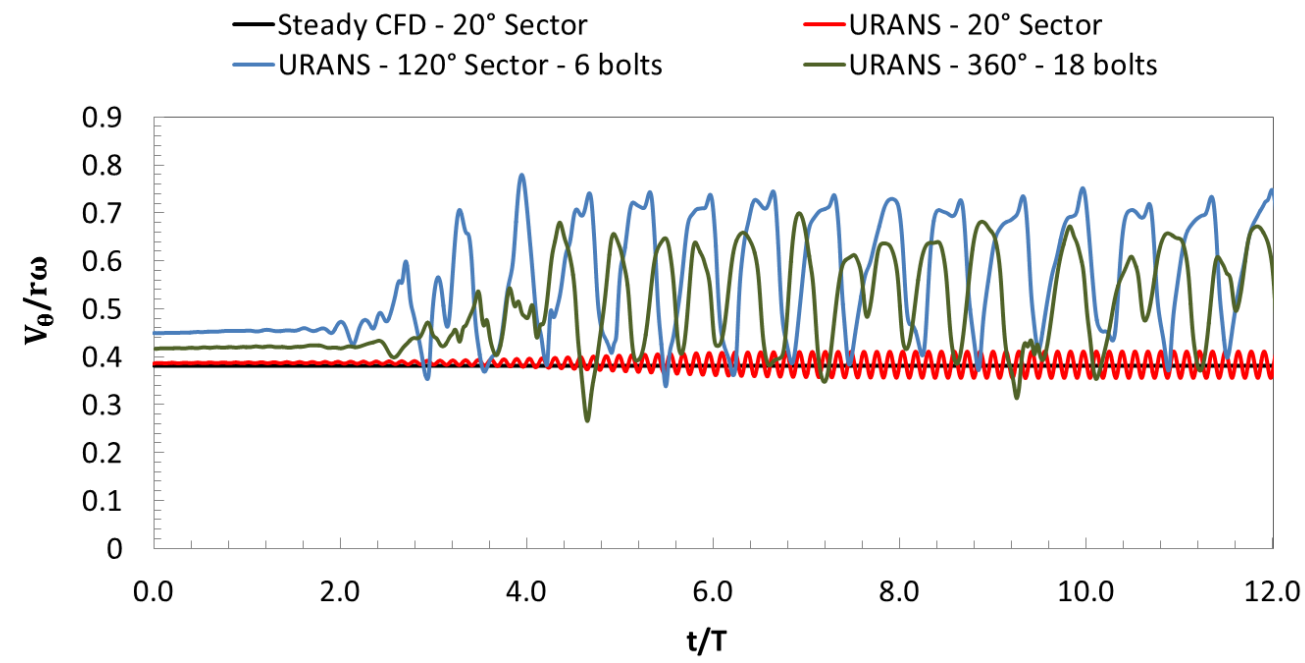

Figure 5. Instantaneous non-dimensional swirl inboard of bolt $\mathrm{B} 1\left(\Theta=10^{0}, \mathrm{r} / \mathrm{b}=0.82, \mathrm{x} / \mathrm{s}=0.4\right.$ from disc surface) - Steady CFD $20^{\circ}$ sector, URANS $20^{\circ}-1$ bolt, $120^{\circ}-6$ bolts and $360^{\circ}-$ 18bolts model

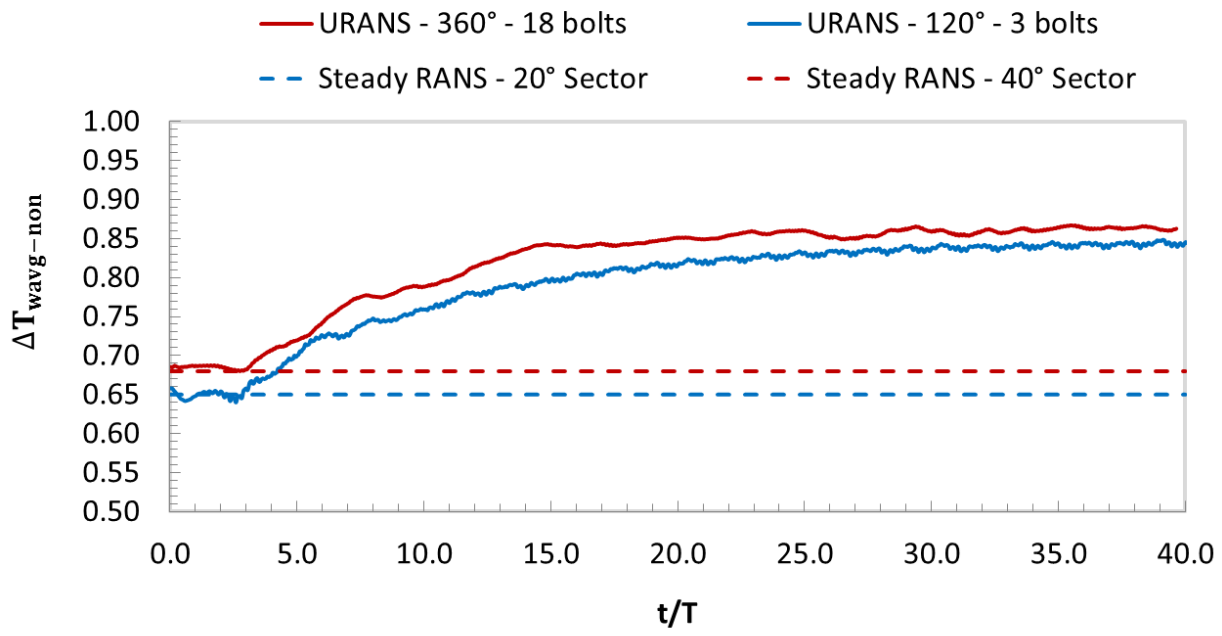

Figure 6. Convergence of area averaged disc surface temperature - URANS $120^{\circ}-3$ bolts and $360^{\circ}-18$ bolts calculations 
For submission to the Journal of Mechanical Engineering Science (Part C, Proc. IMechE)

(a)

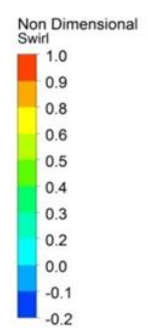

(b)

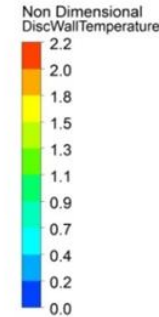

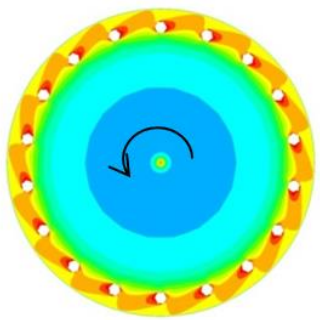

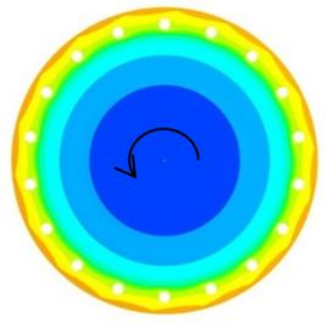

Steady CFD
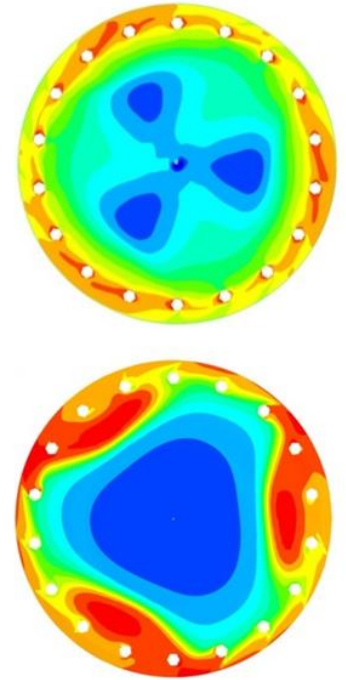

Unsteady RANS - $\mathrm{t} / \mathrm{T}=0.01$

Figure 7. Contours of non-dimensional swirl at $\mathrm{x} / \mathrm{s}=0.25$ from the disc surface and the disc wall temperature - Steady CFD and instantaneous values from URANS calculation after 40 disc rotations $-360^{\circ}-18$ bolts case

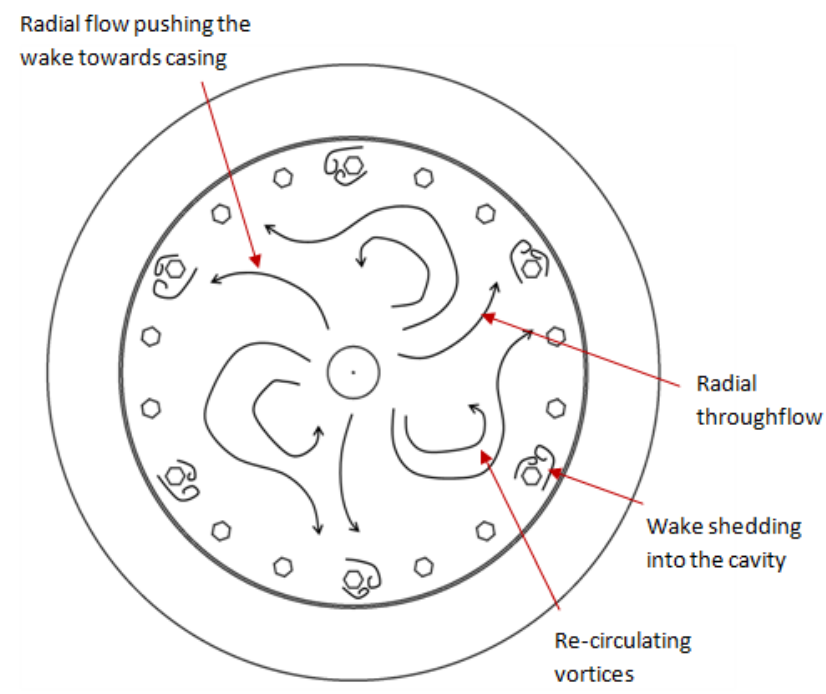

Figure 8. Schematic of the flow dynamics within the cavity for low throughflow conditions 
For submission to the Journal of Mechanical Engineering Science (Part C, Proc. IMechE)

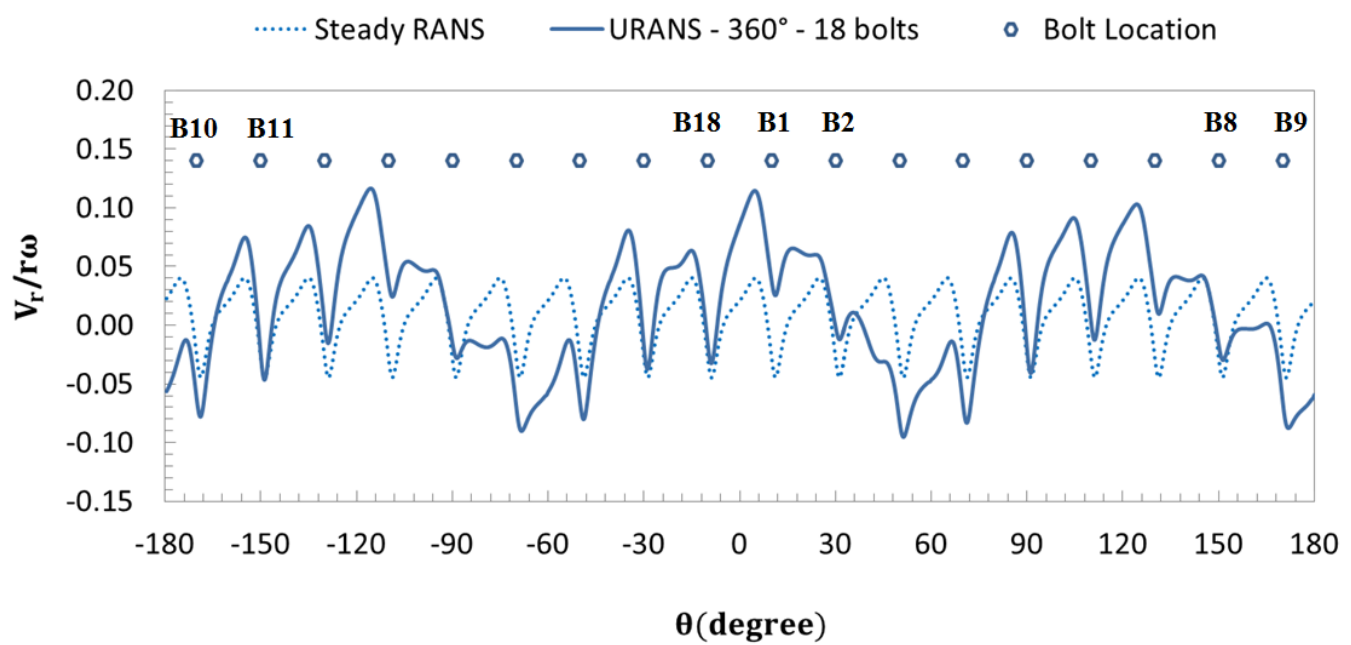

Figure 9. Circumferential variation of non-dimensional radial velocity inboard of bolts $(\mathrm{r} / \mathrm{b}$ $=0.82, \mathrm{x} / \mathrm{s}=0.4$ from disc surface) after 40 disc rotations at $\mathrm{t} / \mathrm{T}=0.01$

(a)

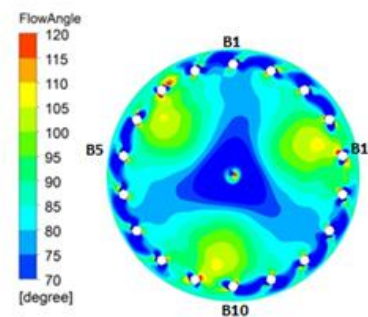

$\mathrm{t} / \mathrm{T}=\mathbf{0 . 0 1}$

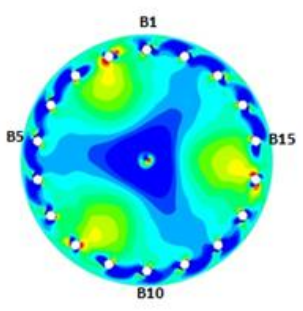

$\mathrm{t} / \mathrm{T}=\mathbf{0 . 1 5}$

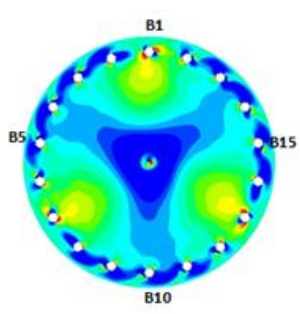

$\mathbf{t} / \mathbf{T}=\mathbf{0 . 2 9}$ (b)

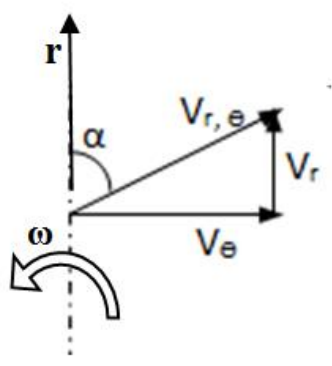

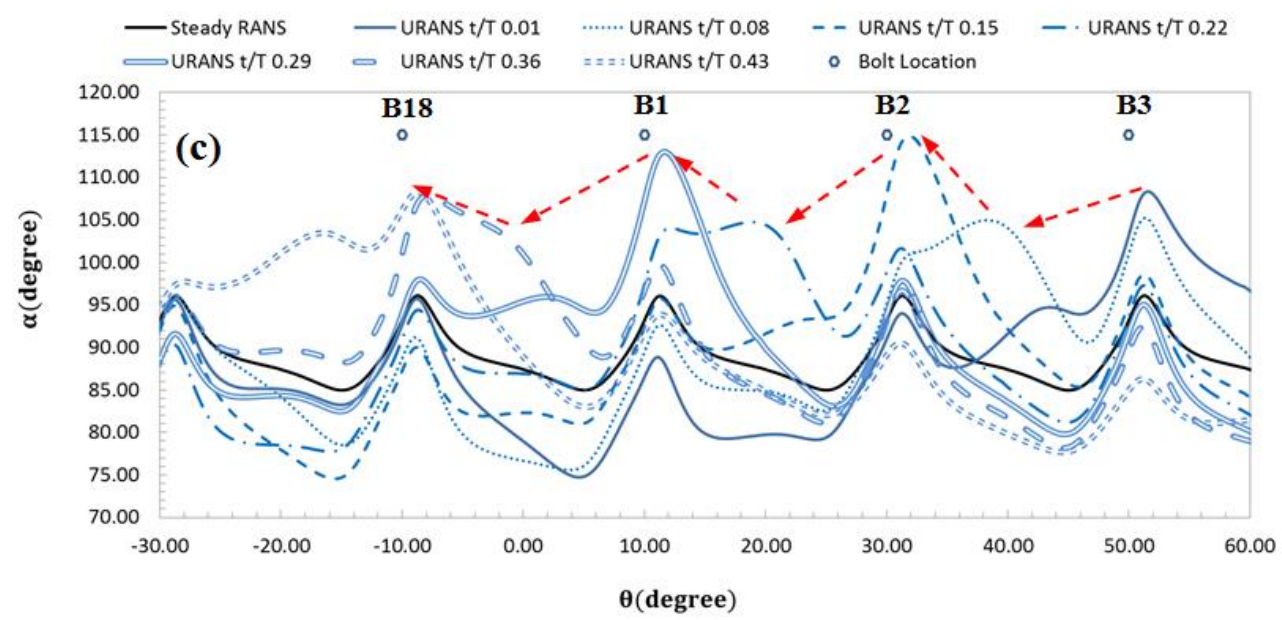

Figure 10. (a) Contour plot of flow angle at various times, (b) defenition of flow angle and (c) Circumferential variation of non-dimensional flow angle inboard of bolts for a $90^{\circ}$ sector $(\mathrm{r} / \mathrm{b}$ $=0.82, \mathrm{x} / \mathrm{s}=0.4$ from disc surface) after 40 disc revolutions 
For submission to the Journal of Mechanical Engineering Science (Part C, Proc. IMechE)

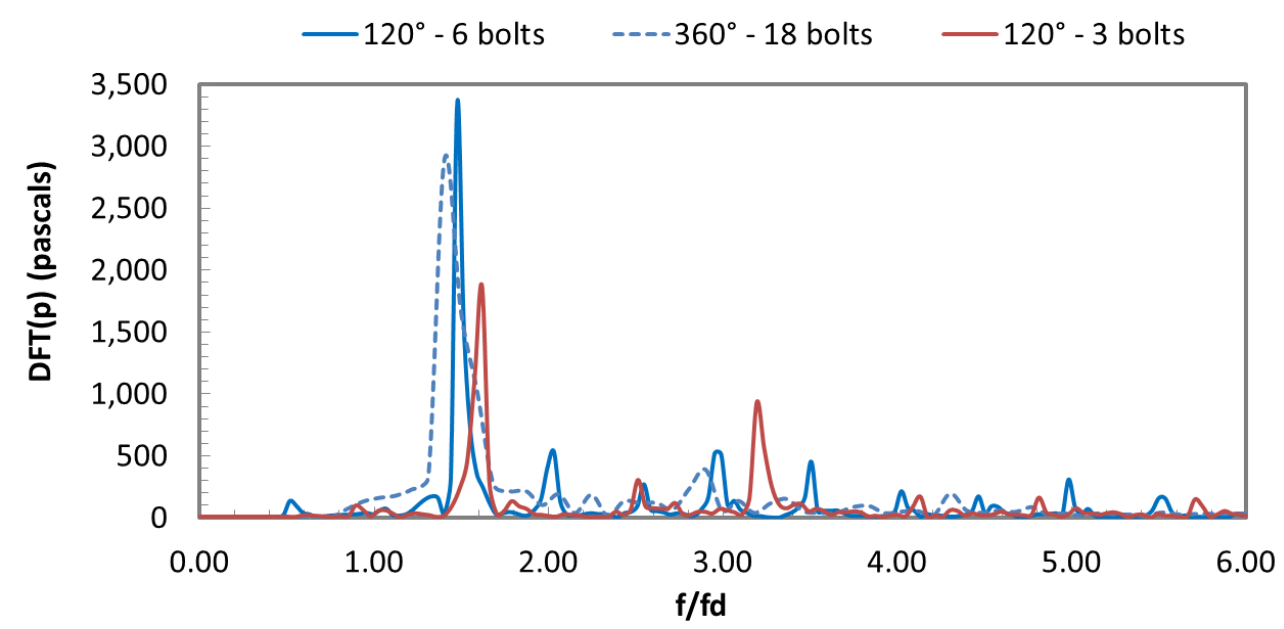

Figure 11. Discrete Fourier Transform of the pressure inside the cavity (in the rotating frame) from $360^{\circ}$ and $120^{\circ}$ models

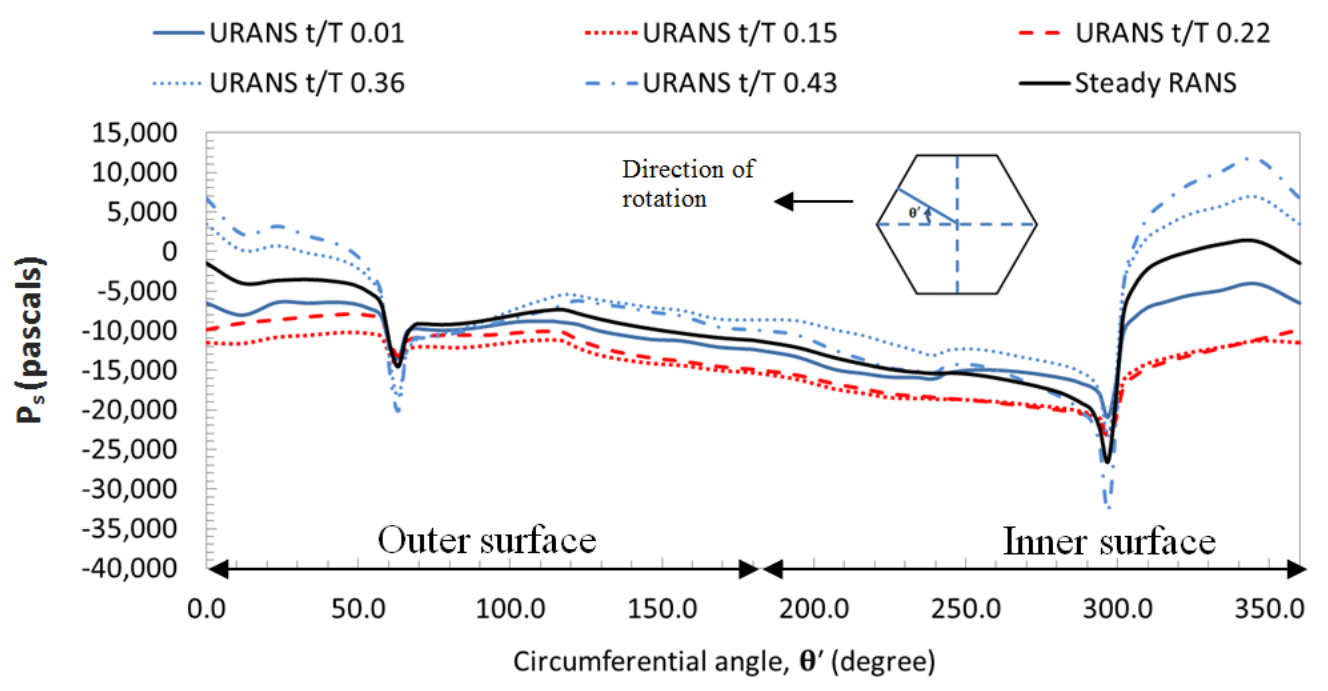

Figure 12. Static pressure distribution along the circumference of bolt $\mathrm{B} 1$, at $\mathrm{x} / \mathrm{s}=0.25$ from disc surface at various times after 40 disc revolutions 
For submission to the Journal of Mechanical Engineering Science (Part C, Proc. IMechE)

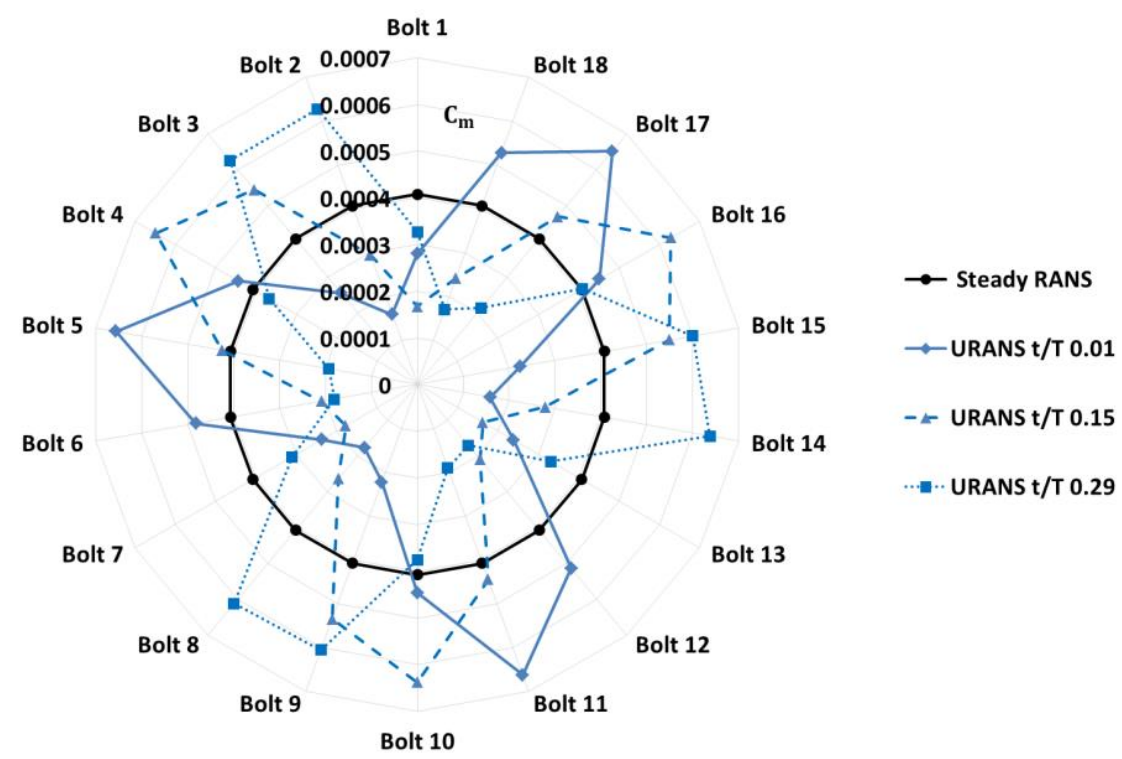

Figure 13. Moment contribution from individual bolts - Steady RANS and Instantaneous values from the URANS calculation.

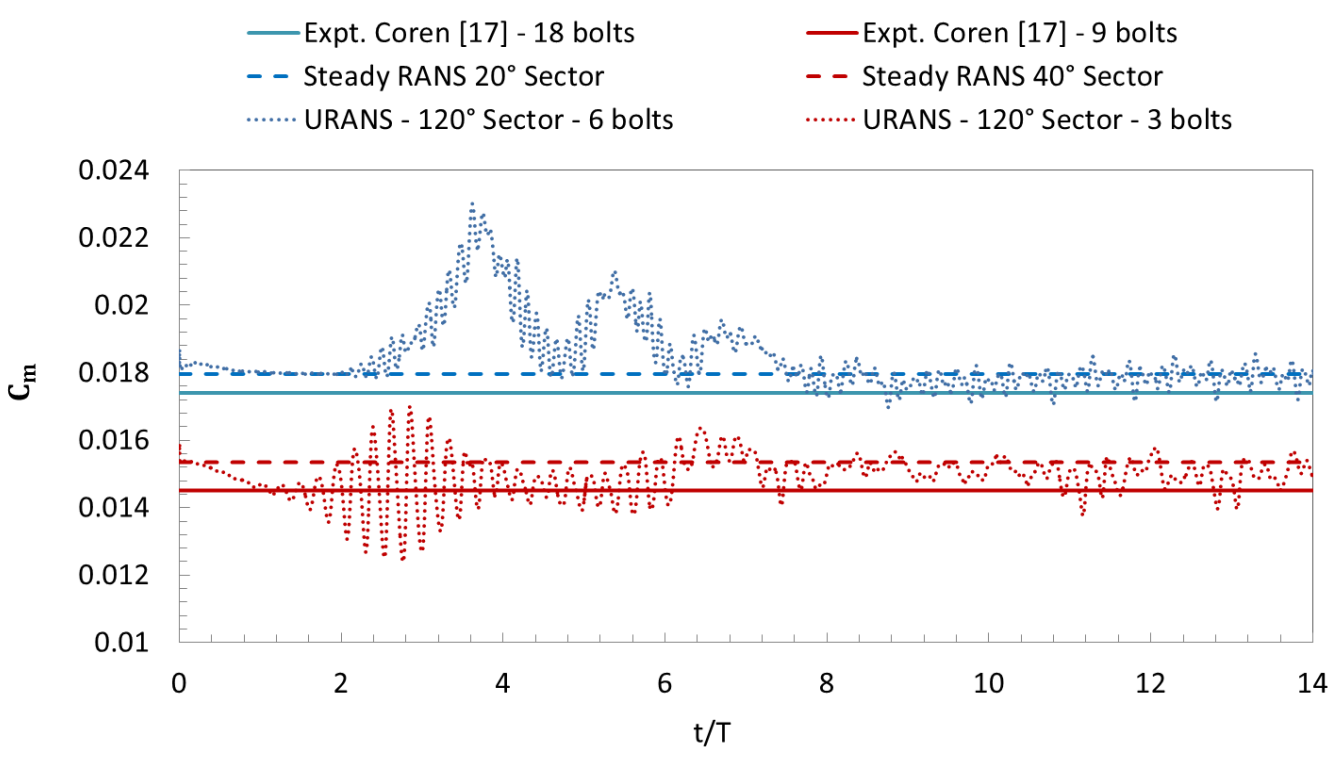

Figure 14. Comparison of instantaneous values of $\mathrm{C}_{\mathrm{m}}$ from URANS $120^{\circ}-6$ bolts and $120^{\circ}-3$ bolts calculations with steady CFD values and Coren's [17] experimental data. 
For submission to the Journal of Mechanical Engineering Science (Part C, Proc. IMechE)
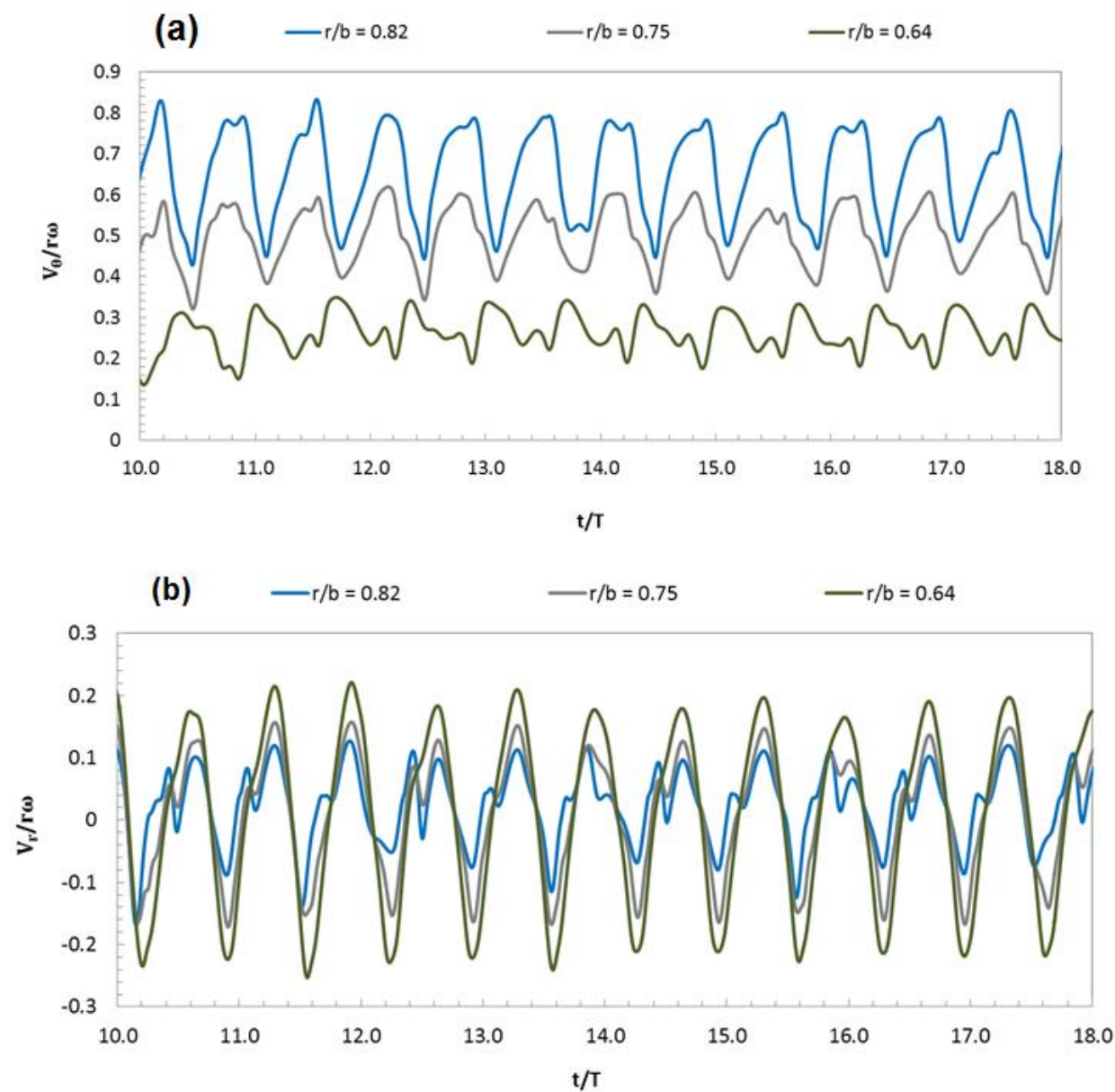

Figure 15. Instantaneous non-dimensional (a) swirl and (b) radial velocity at three locations inboard of the bolt $\mathrm{B} 1$ from $360^{\circ}-18$ bolts URANS calculation $-\Theta=10^{\circ}, \mathrm{x} / \mathrm{s}=0.4$ from disc surface

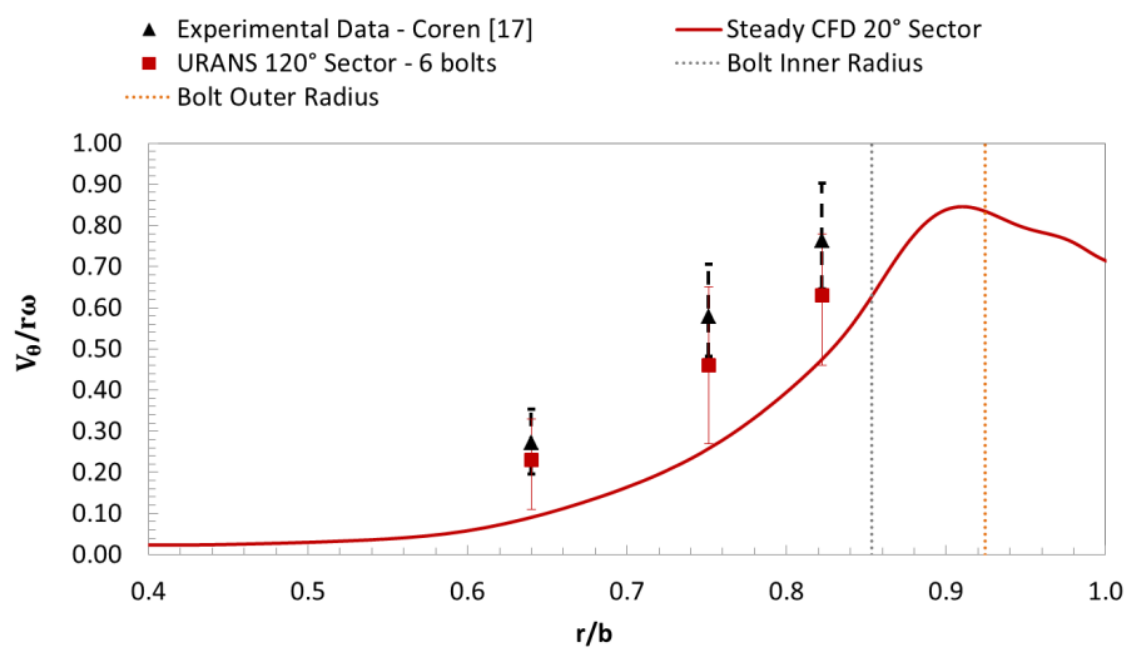

Figure 16. Non-dimensional swirl at $\mathrm{x} / \mathrm{s}=0.4$ - steady state $20^{\circ}$ sector CFD, circumferentialaveraged value from URANS $120^{\circ}-6$ bolts case and experimental RMS value from Coren's [17] measurement -18 bolts case 
For submission to the Journal of Mechanical Engineering Science (Part C, Proc. IMechE)

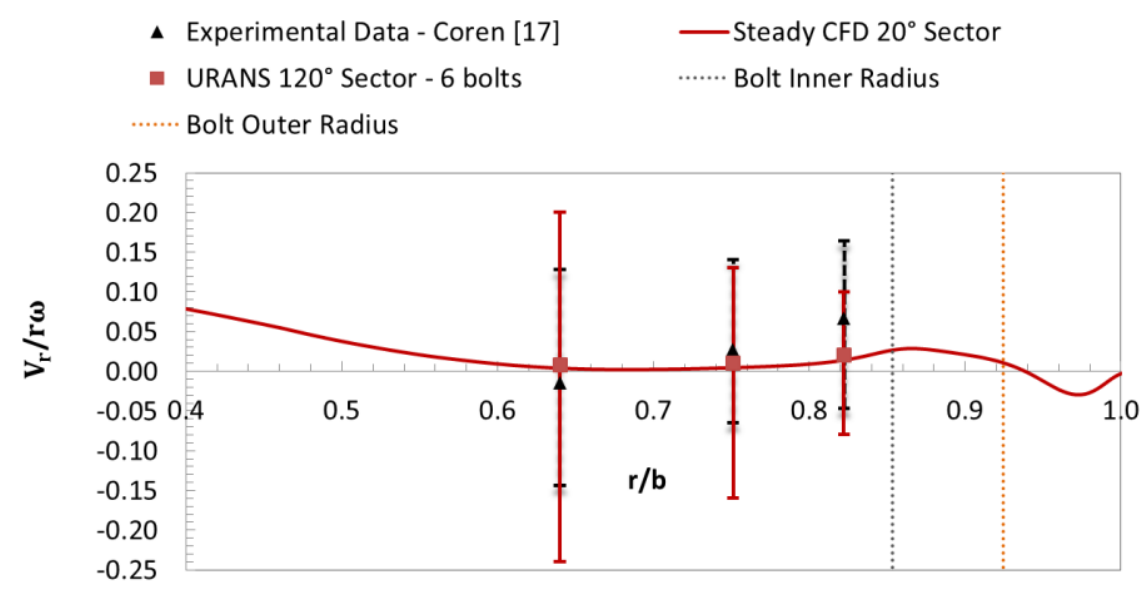

Figure 17. Non-dimensional radial velocity - steady state $20^{\circ}$ sector CFD, circumferentialaveraged value from URANS $120^{\circ}-6$ bolts case and experimental RMS value from Coren's [17] measurement -18 bolts case

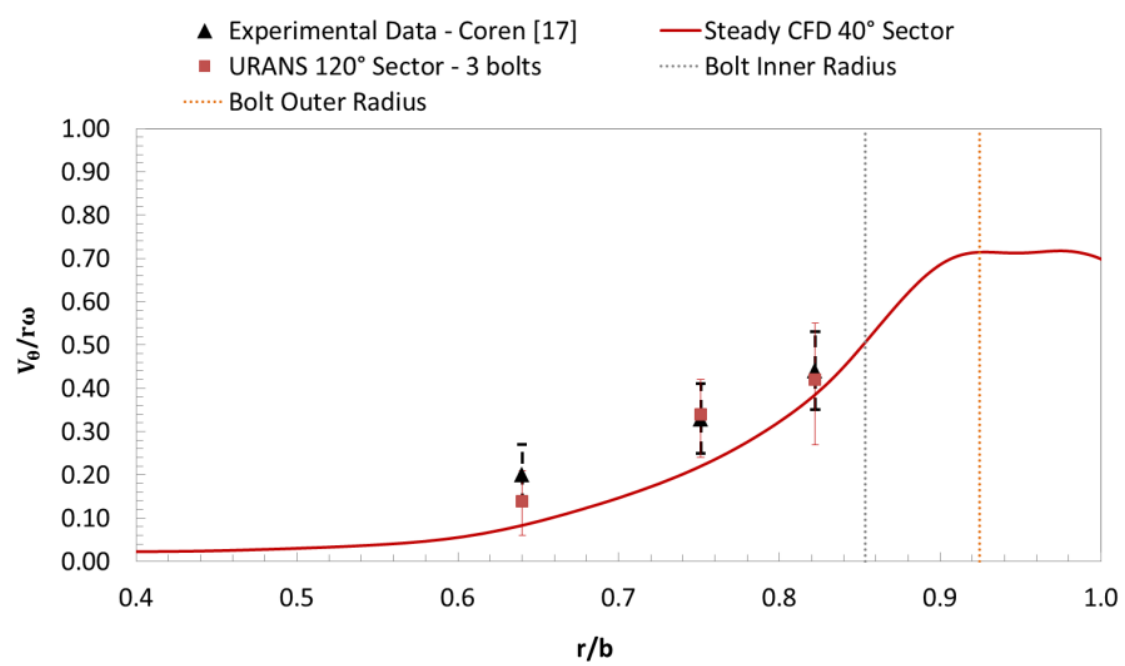

Figure 18. Non-dimensional swirl - steady state $40^{\circ}$ sector CFD, circumferential-averaged value from URANS $120^{\circ}-3$ bolts case and experimental RMS value from Coren's [17] measurement -9 bolts case 
For submission to the Journal of Mechanical Engineering Science (Part C, Proc. IMechE)

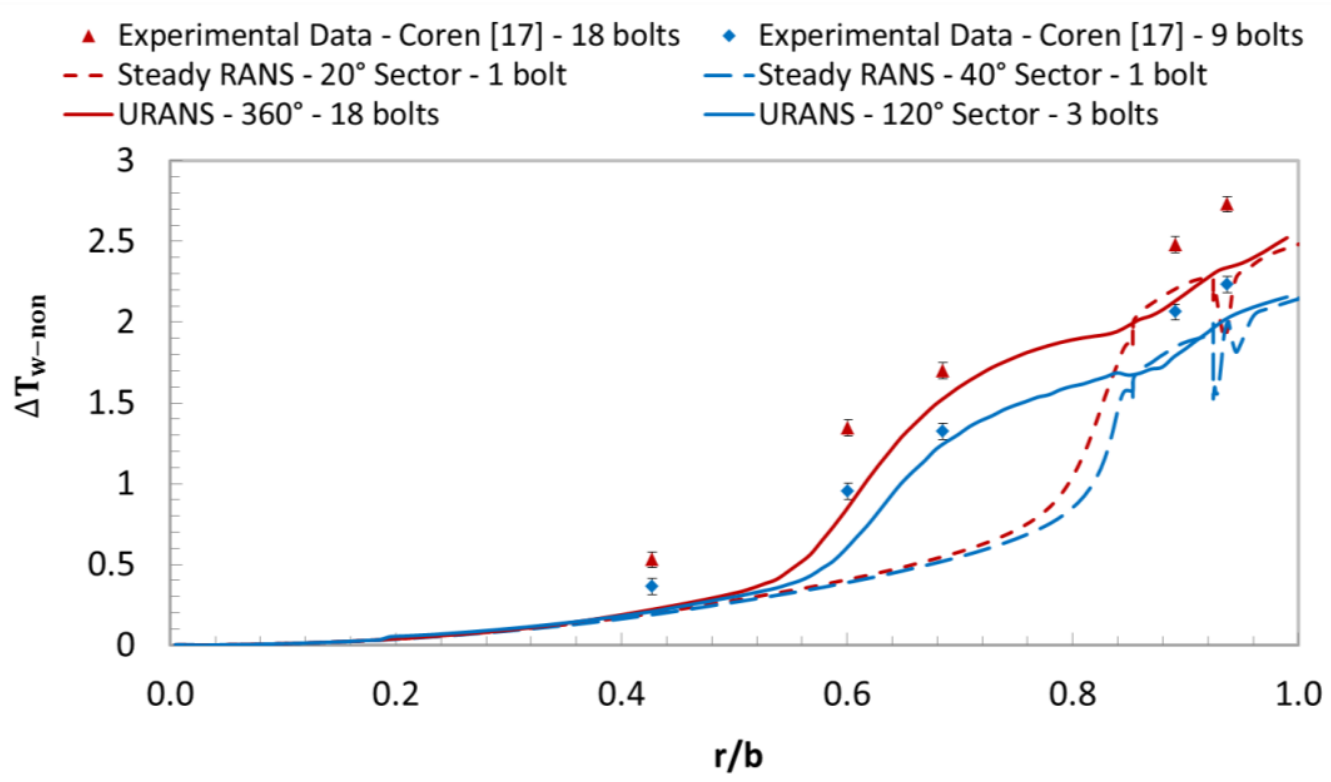

Figure 19. Comparison of non-dimensional adiabatic rotor wall to inlet air temperature difference for 18 and 9 bolts case from steady CFD, circumferential average data from URANS calculation and experimental data from Coren [17] 